\title{
Inventario, clasificación y génesis de los colapsos del terreno en la Masa de Agua Subterránea Mancha Occidental I
}

\author{
K. Bórnez Mejías ${ }^{(1)}$, M. Mejías Moreno(2), C. Camuñas Palencia(2), J. del PozoTejado(2) \\ y A. del Moral Fernández del Rincón ${ }^{(3)}$
}

(1) Universidad Autónoma de Barcelona (UAB). Centre de Recerca Ecològica i Aplicacions Forestals (CREAF). Edificio C.

E-08193 Bellaterra (Cerdanyola del Vallès)

kevin.bornez.mejias@gmail.com

(2) Instituto Geológico y Minero de España, Ríos Rosas, 23, 28003 Madrid

m.mejias@igme.es

c.camunas@igme.es

j.delpozo@igme.es

(3) Centro de Interpretación y Documentación del Agua y los Humedales Manchegos,

Travesía los Molinos, 1, 13250 Daimiel (Ciudad Real)

cidahm@aytodaimiel.es

\begin{abstract}
RESUMEN
Se presenta un estudio detallado sobre los colapsos del terreno, que se han producido en los últimos años en la zona central de la Masa de Agua Subterránea Mancha Occidental I, provincia de Ciudad Real. El principal origen de los colapsos es el hundimiento del techo de cavidades kársticas, como resultado de un rápido e inusual ascenso piezométrico, debido a las abundantes e intensas precipitaciones, como las que tuvieron lugar en el periodo húmedo, 2009-2013, lo que trajo consigo un lavado del sistema kárstico, la circulación del agua por sumideros y canales preferentes, así como la propia disolución del material calcáreo. Esta fase de ascenso piezométrico vino precedida de un descenso continuado de los niveles, motivada por la secuencia seca 2000-2009 y el intenso aprovechamiento de las aguas subterráneas mediante bombeos.

Para conseguir un óptimo conocimiento del área de estudio, se ha realizado un importante trabajo de localización, medición y clasificación de cada uno de los hundimientos. Unido a ello, se han recopilado, ampliado y actualizado los datos de piezometría, con un nivel de detalle muy importante. Se han podido diferenciar cuatro tipos de colapsos: colapsos aluviales (entre los que figuran los relacionados con las turberas), colapsos en zonas de dolina, colapsos lagunares y colapsos de tipo intermedio. Se ha observado que, con el paso de los años, los hundimientos que se producen tienen menores dimensiones. Por último, se han deducido las zonas que presentan una mayor susceptibilidad para que se produzcan nuevos colapsos en lugares como el cauce del río Guadiana, las áreas lagunares y algunas zonas de dolinas.
\end{abstract}

Palabras clave: Acuífero kárstico, colapsos del terreno, MASb Mancha Occidental I, variaciones del nivel piezométrico

\section{Inventory, classification and genesis of the ground collapses in the groundwater body of the Western Mancha I}

\begin{abstract}
This paper presents one of the first detailed studies about the ground collapses that have taken place in recent years in the central area of the groundwater body of the Western Mancha I, in the province of Ciudad Real. The main source of the collapses is the breakdowns of the roof of the karst cavities, as a result of a rapid and unusual increase in the groundwater, due to the widespread and intense rainfall, such as those that took place in the wet period (2009-2013). This brought about a washing of the karstic system, the movement of water through sinks and preferential channels, which had been dry for decades, as well as dissolution of the chalky material itself. This ascent phase of the groundwater was preceded by a steady decrease in the piezometric levels, caused by prolonged drought and over-exploitation through pumping.
\end{abstract}


To obtain an optimum knowledge of the area of study, important research has been done to localize, measure and classify each of the collapses. Along with this, we have compiled, expanded and updated the data of the piezometry, to a high level of detail. We have been able to distinguish four types of ground collapses: alluvial collapses, collapses in areas of dolines, lagoon collapses and of intermediate types of collapses.

It is also evident that with the passage of years, the collapses that have been produced are of lesser dimensions. Finally, we have deduced the areas which have a greater susceptibility for new collapses, in places such as the river Guadiana, the lagoon areas, and some areas of dolines.

Keywords: groundwater body of the Western Mancha I, ground collapses, karst aquifer, piezometric variation

\section{ABRIDGED ENGLISH VERSION}

\section{Introduction}

The groundwater body of the Western Mancha I is located in the high basin of the Guadiana River, specifically in the province of Ciudad Real.

The geological characteristics, mainly the karstification, are conducive to the existence of this great aquifer that occupies an area of about $5500 \mathrm{~km}^{2}$, in a zone where the intensive use of groundwater has occurred, causing average declines of 30 metres in the piezometric level.

But this piezometric descent was not only due to intense extraction, but rather to the presence of a long period of drought, and it was not until December 2009, when intense and abundant precipitation of a small wet cycle, gave rise to an unusual and rapid increase in the piezometric levels, which did not stop rising until mid-2014, favouring the recovery of the wetlands, and leading to a series of collapses of the ground between the years 2010 and 2013, mostly due to the collapse of the roof of the karst cavities.

\section{Objectives}

The main objective of the work carried out has been to expand the knowledge about the formation of the ground collapses, in the area of the upper Guadiana. Likewise, we aimed to establish a first typology of the collapses of the ground, which will help us to qualify the area according to their greater or lesser susceptibility to new collapses.

\section{Methods}

To achieve the proposed objectives, considerable fieldwork has been necessary; where, based firstly on an extensive knowledge of the area of study, the localisation of the collapses that were covered or undocumented was carried out and measurements were taken of these collapses where possible.

The next step was the acquisition and updating of piezometric information, in which not only were IGME and the CHG measures used, but also thirty new piezometers in the surrounding areas of the collapses, thus providing a sufficient amount of data to observe possible changes in the direction of the groundwater flow.

With all of this data we were able to classify of each of the collapses, according to their characteristics, thus allowing us to analyse the susceptibility of the zone regarding possible new collapses.

\section{Geological framework of the study area}

The groundwater body Western Mancha l, has an approximate surface area of 2,000 $\mathrm{km}^{2}$, and is located in the upper basin of the Guadiana River. We find a gentle relief, with an altitude ranging between 600 and 750 metres above sea level. The rivers that cross the mass are the Gigüela, Záncara, Azuer and Guadiana.

The Western Mancha I groundwater body is composed mainly of materials from the Tertiary and Quaternary periods, composed of detritus deposits, limestone, marly limestone and "rañas". On the limestone of the Upper Pliocene an intense karstification has developed, resulting in the main aquifer formation, with considerable extension and potency whose natural discharge occurs in the Ojos del Guadiana and other springs along the upper course of the river (Fig. 2).

With regard to the climate, the area has a mean precipitation of around $400 \mathrm{~mm}$ per year, distributed irregularly throughout the year, which impacts directly on the surface and groundwater (Fig. 3).Focusing 
on recent years, it is necessary to point out the existence of a wet period (2009-2014), thanks to which, the piezometric aquifer level has risen on average more than 20 metres; also producing an increase of the flow of the rivers. This phenomenon has given rise to the problem of the ground collapses.

\section{Location and characteristics of the ground collapses}

The ground collapses have occurred only in the body of groundwater the Western Mancha l, because it has a piezometry closer to the surface which, moreover, presents a considerable karstification. In total 34 collapses have been identified and georeferenced in the municipalities of Villarrubia de los Ojos and Daimiel.

The vast majority of the collapses are located in areas near to the riverbed of the Guadiana River, as well as in the lagoons located northwest of Daimiel; in this area it is possible to appreciate what seems at first to be an alignment between the collapses of the area (Fig. 4).

Of the total collapses there is evidence that 18 occurred in 2010. In 2011 four new collapses appeared, as in 2013. On the other hand, a total of 5 collapses have no data regarding the specific date of the collapse. Finally there is also evidence of another three collapses, but in this case from 1997, and therefore not related to the current hydrodynamic situation (Table 1).

In most of the located collapses measurements were taken, due to this we know that they tend to have a circular form, although by observing in detail the measurements of each it has been proven that they are not completely circular in all the cases, but they do appear with a certain direction (ellipsoidal collapses) (Table 2).

In regard to the dimensions according to the year of the collapse, it has been possible to verify that those produced in the year 2010 have average diameters superior to 10 metres, higher therefore than those produced later. These collapses have occurred at the time in which the level of groundwater was at a greater depth, which may lead to the idea that the deep karst is found to be more developed than in the more superficial areas.

\section{Origin of the collapses}

To investigate the origin of the collapses, both the main water chemistry parameters and the groundwater level were taken into account. As a consequence of this we can observe the absence of relationship between the collapses and the chemical evolution of the water in recent years. On the other hand, we did observe that collapses were directly related to the sudden rise of piezometric levels (Fig. 5), which caused the collapse of part of the underground karst cavities.

To analyse in detail the piezometric evolution of recent years, we have made a series of very detailed isopiestic maps (Figs. 6 and 7), thanks to which the decrease in piezometric depression can be seen, as well as changes in the flow direction and the appearance of the collapses.

\section{Typology of collapses}

Considering the analysis of the hydrogeological, geomorphological and geological characteristics in the study area, we have made a classification of the types of collapses, according to their structural characteristics, genesis and depth of the level of groundwater at the time of the collapse (Table 3).

Four typologies have been identified: the first of these is the typology of the alluvial collapse; secondly the collapses in the doline areas; a third group are formed by lagoon collapses and finally, a last typology that refers to an intermediate type of collapse.

According to the applied criterion, we have considered from this knowledge that the collapses in which the depth of the groundwater was equal to or less than 11 metres, were caused by predominantly horizontal flows, all of them alluvial and lagoon. In contrast, when the water depth exceeds 11 metres, the vertical flows begin to act.

\section{Analysis of susceptibility of land for new collapses}

We cannot anticipate or predict, from the space-time point of view, the appearance of this phenomenon, but it is possible to suggest hypothetically, some considerations regarding the possible spatial distribution of future ground collapses, especially through the delimitation of areas that, from the 
Bórnez Mejías, K., et al., 2017. Inventario, clasificación y génesis de los colapsos del... Boletín Geológico y Minero, 128 (1): $43-68$

hydrogeological and geomorphological point of view, meet the appropriate characteristics in order to produce this phenomenon.

For this purpose a few maps that represent the susceptibility of the ground to new collapses have been prepared, having taken into account the collapses now present in each one of the classified types, qualifying areas according to a greater or lesser predisposition to the formation of collapses. In this sense, the zone with the highest susceptibility is the riverbed of the Guadiana River.

\section{Conclusions}

In the Western Mancha I groundwater body we currently find a high concentration of ground collapses, specifically 34. Most of them have originated in the last four years. As the years pass, the new collapses produced have smaller dimensions and have their origin in the sinking of karst cavities due to the rise of the groundwater level. There are different types of collapses, according to their hydrogeological and geomorphological characteristics, and the possibility of new collapses appearing cannot be ruled out.

\section{Introducción}

La Masa de Agua Subterránea (MASb) Mancha Occidental I, se localiza en la Cuenca alta del río Guadiana, concretamente en la provincia de Ciudad Real. Esta MASb junto con Mancha Occidental II y Rus-Valdelobos, conforma lo que hasta hace pocos años se denominaba Unidad Hidrogeológica 04.04 Mancha Occidental y, anteriormente, Sistema Acuífero 23 (figura 1).

Las características hidrogeológicas, principalmente la karstificación, propician la existencia de este gran acuífero regional que ocupa una superficie de $5500 \mathrm{~km}^{2}$, en una zona donde se ha llevado a cabo, desde los años setenta del pasado siglo, un aprovechamiento intensivo de las aguas subterráneas, provocando un descenso del nivel piezométrico de hasta 30 metros al final de la secuencia seca 1980-1995; lo que trajo consigo importantes modificaciones, o

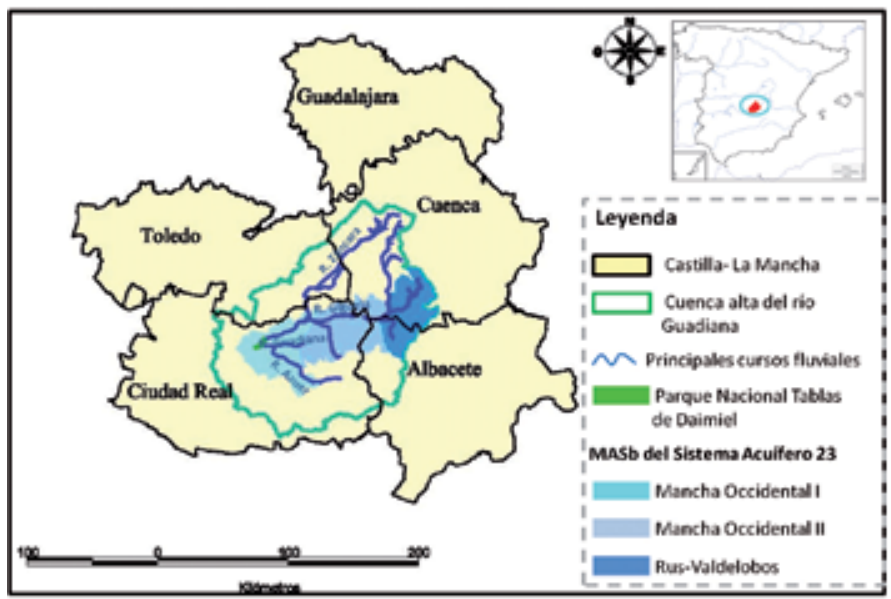

Figura 1. Mapa de localización del Sistema Acuífero 23 y las MASb incluidas en el mismo.

Figure 1. Map of location of the Aquifer System 23 and groundwater bodies in the same. incluso la desecación, en la mayoría de los humedales presentes en la zona, destacando el caso del Parque Nacional de las Tablas de Daimiel. Estos descensos también ocurrieron en las otras MASb limítrofes, como la del Campo de Montiel, en la que se midieron descensos del orden de 10 a 40 metros, provocando la desecación de los manantiales y disminuyendo drásticamente el flujo de agua subterránea que se transfería a las MASb situadas al norte, como Mancha Occidental II (Montero, 1994 y 2000, Rodríguez, 2014).

El aumento en las extracciones de agua subterránea se debió, en gran medida, a la presencia de dos largos periodos de sequía (1979/80-1994/95 y 1998/99-2008/09). No fue hasta diciembre de 2009 cuando las intensas y abundantes precipitaciones dieron lugar a un inusual y rápido aumento de los niveles piezométricos, continuando su ascenso hasta el periodo de aguas altas de 2014. Este proceso conlleva la recuperación de las zonas húmedas, el aporte de agua subterránea al río Guadiana entre los Ojos del Guadiana y las Tablas de Daimiel, y origina una serie de hundimientos del terreno entre los años 2010 y 2013 denominados colapsos.

La mayor parte de estos colapsos se deben al desplome del techo de cavidades de origen kárstico. Tienen una gran importancia desde el punto de vista hidrogeológico y geomorfológico, pero también económico y social, lo que hace de este fenómeno el objeto de investigación del presente artículo.

\section{Objetivos}

El objetivo principal del trabajo de investigación ha sido el de ampliar el conocimiento acerca de la génesis de la formación de los colapsos del terreno, en la zona del Alto Guadiana. Para ello, resulta 
fundamental la localización previa de cada uno de los colapsos que en la mayoría de los casos ya se conocía, gracias a un inventario previo realizado por técnicos del Centro de Interpretación y Documentación del Agua y los Humedales Manchegos (CIDAHM). Una vez conocida dicha ubicación, se podrá obtener una valiosa información en relación a las características geomorfológicas y geométricas.

Tomando como base los datos de la red de observación piezométrica del Instituto Geológico y Minero de España (IGME) y de la Confederación Hidrográfica del Guadiana (CHG), junto a medidas piezométricas específicas tomadas en las zonas aledañas a los colapsos, se han podido realizar mapas de isopiezas detallados.

Una vez recopilada y analizada toda la información, se ha establecido una tipología detallada de los colapsos del terreno, de tal forma que se puedan clasificar de acuerdo a sus características hidrogeológicas. Esta clasificación ayudará posteriormente al análisis de la susceptibilidad de aparición de nuevos colapsos en la zona.

\section{Metodología}

Para alcanzar los objetivos propuestos, ha sido necesario un considerable trabajo de campo, en el que, partiendo en primer lugar de un amplio conocimiento de la zona de estudio, se llevó a cabo la localización de aquellos colapsos que se encontraban cubiertos o sin documentar, para lo cual fue necesario la utilización de la teledetección aplicada a Sistemas de Información Geográfica (SIG). Por otro lado, se tomaron medidas mediante telémetro óptico y metro convencional en aquellos colapsos que fue posible. Además, gracias a la cartografía geológica y a las columnas litológicas de los puntos de observación piezométrica de la Confederación Hidrográfica del Guadiana, se pudo analizar la composición del subsuelo en la zona, ya que algunas de estas columnas se encuentran muy cerca de los colapsos.

Para la adquisición y actualización de la información piezométrica, se ha contado no sólo con las medidas del IGME y la CHG, sino con treinta nuevos piezómetros en los que se han tomado datos de la profundidad del nivel freático mediante una sonda piezométrica en las zonas aledañas a los colapsos, entre los meses de mayo y junio de 2014. Se cuenta con un número suficiente de datos para observar los posibles cambios en la dirección y flujo del agua subterránea.

Con todo ello se ha podido llevar a cabo la clasificación de cada uno de los colapsos, de acuerdo a sus características, para de esta forma poder analizar la susceptibilidad de la zona ante nuevos posibles hundimientos.

\section{Marco geográfico y geológico del área de estudio}

\section{Marco geográfico}

La MASb Mancha Occidental I cuenta con una superficie de $2002,80 \mathrm{~km}^{2}$, se localiza en la cuenca alta del río Guadiana, entre las estribaciones de los Montes de Toledo al Oeste, Sierra de Altomira al Norte, Campo de Calatrava al Suroeste, Campo de Montiel al Sur y Llanos de Albacete al Este.

La zona de estudio tiene un relieve suave, con una altitud que oscila entre los 600 y los 750 m s.n.m., destacando las mayores cotas en la zona sur y este de la Llanura Manchega.

El límite oeste de la MASb Mancha Occidental I se localiza en las proximidades de los núcleos de Malagón y Fernán Caballero. Al igual que en el borde norte (zona de Villarrubia de los Ojos), aparecen materiales del Ordovícico, principalmente cuarcitas y pizarras, con algunas estructuras tectónicas de dirección noroeste-sureste y oeste-este (IGME, 1985 y 2000).

Los principales cursos fluviales que trascurren por la MASb son: Gigüela, Záncara, Azuer y Guadiana; ríos que no poseen abundante caudal. Drenan la cuenca de Este a Oeste, confluyendo sus aguas en el entorno del Parque Nacional de las Tablas de Daimiel (figura 2).

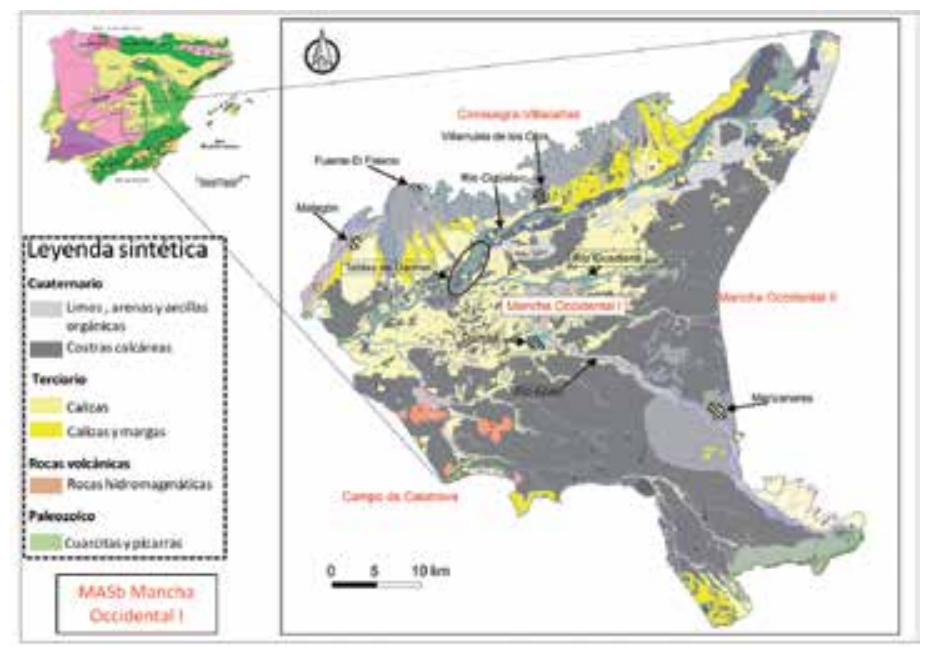

Figura 2. Mapa geológico sintético de la MASb Mancha Occidental I (Mejías, 2014).

Figure 2. Synthetic geological map of the groundwater body Mancha Occidental I (Mejías, 2014). 


\section{Contexto geológico regional}

La MASb Mancha Occidental I se localiza geográficamente en la Llanura Manchega, la más extensa de la Península lbérica, y geológicamente en la Cobertera Tabular de la Meseta, modelada a finales del Plioceno-Pleistoceno, y que se mantiene poco modificada dada la escasa capacidad del Guadiana y sus afluentes para encajarse, básicamente al no haberse producido una tectónica intensa. Destaca la presencia de calizas de edad terciaria, principalmente del Plioceno, lo que da lugar a un acuífero kárstico de notable extensión y potencia, que oscila entre los 30 y 120 metros de espesor, cuya descarga natural se produce en los Ojos del Guadiana y otros manantiales a lo largo del curso alto del río (García Rodríguez, 1996a). Por otro lado, es importante comentar que el escaso relieve de la Llanura Manchega, condicionado por una tectónica suave reducida a ondulaciones y fallas normales, ha propiciado fenómenos endorreicos, donde destaca la presencia de charcas y lagunas estacionales, en muchos casos salobres (González y Vázquez, 2007).

\section{Climatología}

En la zona se registra una precipitación media en torno a $400 \mathrm{~mm}$ anuales, que se distribuyen de forma irregular a lo largo del año. Los máximos pluviométricos se producen en invierno, seguido de la primavera y el otoño; en el verano es cuando se produce el mínimo de precipitaciones (Mejías, 2014). Debido al interés e importancia de las precipitaciones para la evolución de la MASb, y tomando como referencia la estación termopluviométrica de Las Tablas de Daimiel, en la figura 3 se representa un gráfico con la serie histórica de precipitaciones (1960/61 a 2014/15) y la desviación acumulada (Mejías, 2015), que ayuda a comprender la climatología de la zona, así como la evolución piezométrica.

Para conseguir un mejor análisis de estos datos se han diferenciado cinco rangos de precipitación anual, que permiten clasificar un año hidrológico como: muy seco, seco, normal, húmedo o muy húmedo.

De la representación gráfica cabe resaltar la irregularidad de las precipitaciones, lo que va a tener

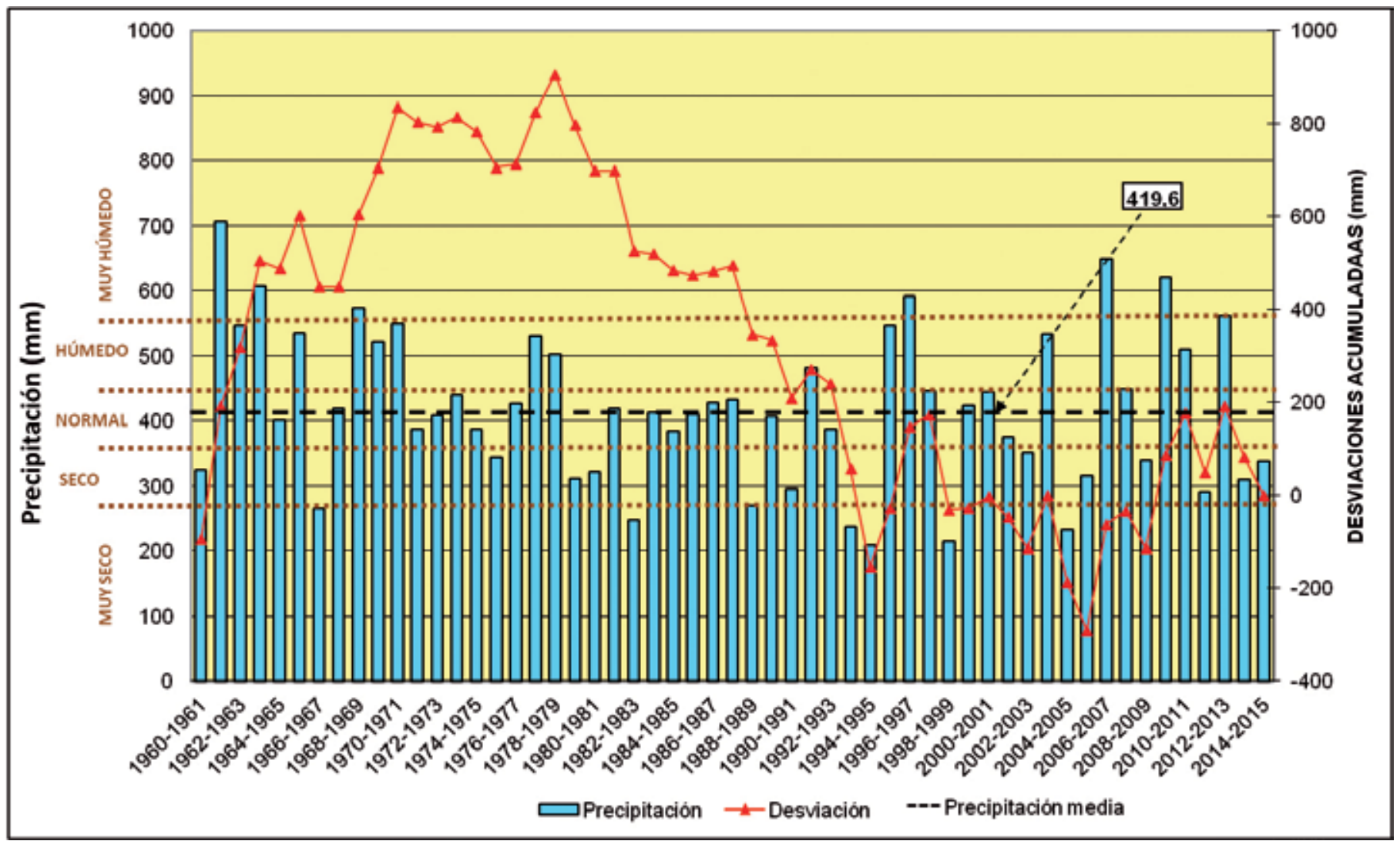

Figura 3. Serie histórica de precipitaciones y desviación acumulada de la estación termopluviométrica de las Tablas de Daimiel (datos de AEMET, Mejías, 2015).

Figure 3. Historical series of precipitation and cumulative desviation of the Tablas de Daimiel Station (Data of AEMET, Mejías, 2015). 
consecuencia directa sobre las aguas subterráneas y superficiales. En los últimos años, hay que señalar la existencia de un periodo húmedo, en el que además se observan años con un carácter muy húmedo, destacando los años hidrológicos 2006/07, 2009/10, 2012/13.

Es precisamente a raíz del periodo de precipitaciones 2009-2013, cuando los niveles piezométricos del acuífero ascienden, como media, algo más de 18 metros durante estos cuatro años, produciéndose también un aumento del caudal de los ríos. Este fenómeno ha dado lugar al problema de los colapsos del terreno, que se analiza a lo largo de este trabajo. En este escenario antiguos conductos kársticos que quedaron secos cuando bajaron los niveles piezométricos, comenzaron a ejercer nuevamente su función.

\section{Hidrología}

La hidrología va a estar condicionada por toda una serie de factores climáticos, geológicos, geomorfológicos y topográficos, característicos de la zona donde se localiza el acuífero. La cuenca alta del río Guadiana comprende cursos fluviales con escaso caudal, como consecuencia de la poca altitud de su cabecera y la escasez e irregularidad de las precipitaciones.

En cuanto a las aguas subterráneas, hay que vincularlas a las características del sustrato geológico, que conforma un importante acuífero kárstico capaz de albergar gran cantidad de agua, lo que da lugar al gran acuífero manchego, cuya surgencia se produce en los Ojos del Guadiana y Las Tablas de Daimiel. Aunque cabe mencionar que esta dinámica ha estado alterada durante las últimas tres décadas, como resultado del aprovechamiento intensivo de las aguas subterráneas, estas áreas pasaron con los años de ser el rebosadero natural del acuífero de la Llanura Manchega a convertirse en un sumidero, una gran balsa de recarga artificial (García Rodríguez y Llamas, 1996).

No fue hasta el año 2013, cuando la situación comenzó a revertir y el acuífero volvió a resurgir en estas zonas.

\section{Características hidrogeológicas de la MASb Mancha Occidental I}

La MASb Mancha Occidental I está constituida principalmente por materiales del Terciario y Cuaternario, compuestos por depósitos detríticos, calizas, calizas margosas y rañas. El acuífero más importante es el constituido por las calizas miopliocenas, las cuales presentan un importante engrosamiento hacia el este (límite con la MASb Mancha Occidental II), con espesores que en algunos puntos superan los 150 metros. El material calizo conforma un acuífero de carácter libre, con una gran porosidad por karstificación y permeabilidad media-alta, con espesores medios continuos, que según las columnas litológicas realizadas en la zona alcanzarían del orden de los 35-40 metros, y transmisividades comprendidas entre los 50 y $20000 \mathrm{~m}^{2} /$ día (IGME, 1979). En este sentido, se ha tomado como ejemplo una columna litológica (figura 4) realizada por la Confederación Hidrográfica del Guadiana en el año 2008, en el

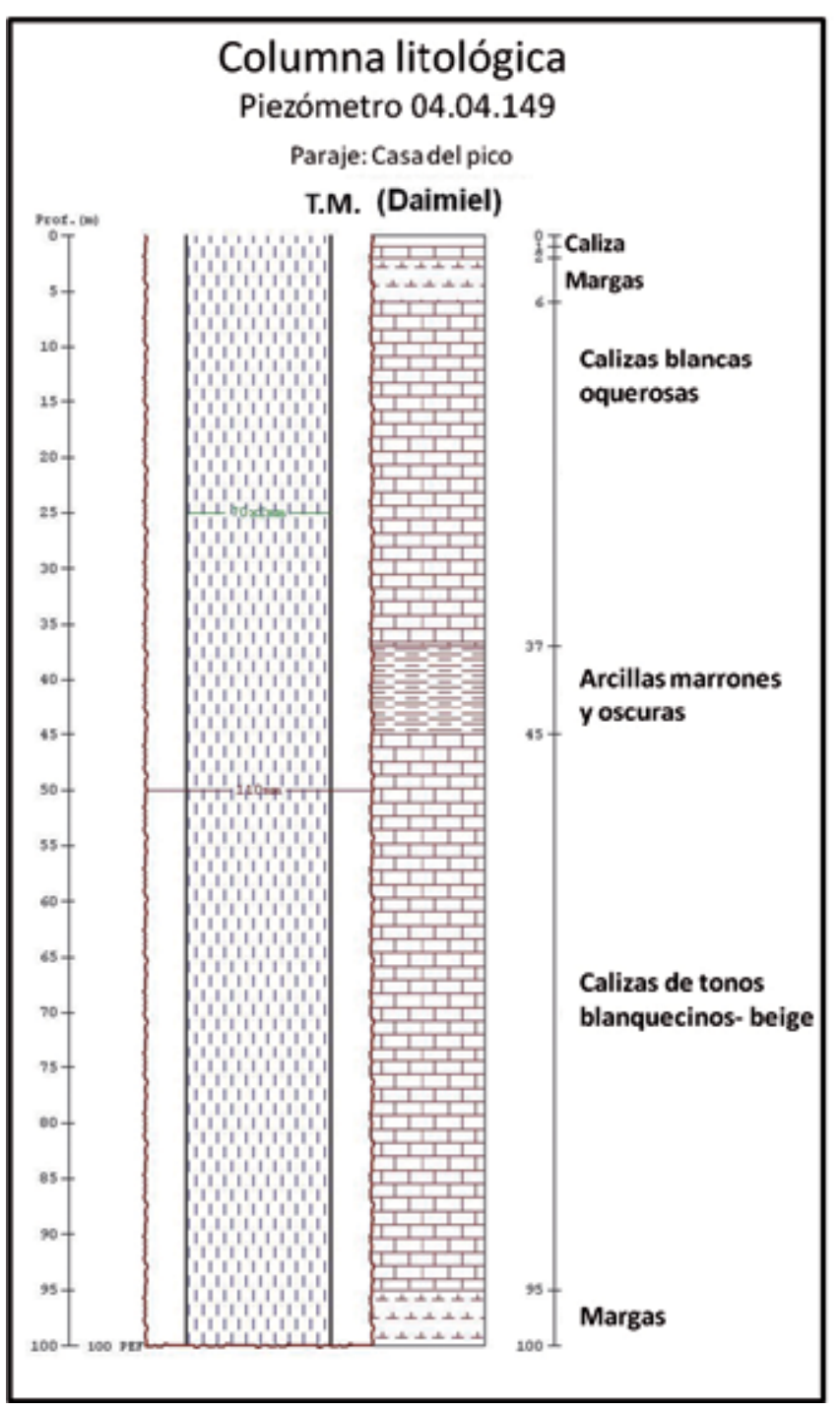

Figura 4. Columna litológica del piezómetro 04.04.149. Confederación Hidrográfica del Guadiana, 2008.

Figure 4. Lithological column of 04.04.149 piezometer. Guadiana Hydrographic Confederation, 2008. 
sondeo identificado como 04.04.149, dentro del término municipal de Daimiel. Esta se encuentra muy próxima a varios de los colapsos localizados en el área. El sondeo tiene 100 metros de profundidad y destaca la alternancia de potentes niveles de caliza (entre 30 y 50 metros) de tonos blanquecinos, intercalados con estratos de menor potencia, en este caso de arcillas y margas. Las margas se encuentran principalmente a muro y a techo del sondeo, mientras que las arcillas lo hacen en la zona central, entre los 37 y los 45 metros de profundidad.

La base impermeable del sistema está constituida por depósitos paleozoicos de baja o nula permeabilidad (CHG, 2013), tales como las pizarras. La MASb Mancha Occidental I ocupa, aproximadamente, el tercio occidental de la antigua Unidad Hidrogeológica 04.04, situándose en la zona más baja del sistema, siendo receptora directa del flujo subterráneo que procede de la MASb Mancha Occidental II, al Este, $y$, en mucha menor medida, de la MASb ConsuegraVillacañas, al Norte.

Las tres masas de agua centrales de la cuenca alta del Guadiana tienen unas relaciones hidrogeológicas importantes, sobre todo Mancha Occidental I y Mancha Occidental II. Su diferenciación se basa en razones físicas que ponen de manifiesto la existencia en Mancha Occidental I de un solo acuífero terciario, mientras que en Mancha Occidental II existen dos horizontes, el superior (mencionado anteriormente, de edad terciaria y cuaternaria) y el inferior (de edad mesozoica) separados por un acuitardo. Este último se compone de un tramo superior arcilloso-arenoso, que se extiende bajo la unidad superior, y por un tramo inferior de conglomerados (García Rodríguez y Llamas, 1996). El sentido del flujo es del acuífero inferior al superior y del Este al Oeste, formando un conjunto que actúa como un embalse subterráneo, cuya descarga natural se produce en el curso alto del río Guadiana (Cruces y Martínez, 2000).

A nivel de Sistema Acuífero 23, el acuífero superior se extiende por $3000 \mathrm{~km}^{2}$. Los materiales que lo componen son calizas y margas del Mioceno Superior y, sobre todo del Plioceno, niveles detríticos superiores del Terciario y Cuaternario y/o materiales volcánicos relacionados con éstos. Dicho nivel superior funciona como un acuífero libre, que se recarga por infiltración del agua de lluvia y por transferencia subterránea. A techo se distingue un nivel detrítico pliocuaternario asentado sobre un tramo calcáreo terciario. En este último la transmisividad depende de la proporción de margas y calizas existentes (Mejías et al., 2012a).

En las calizas del Mioceno superior - Plioceno inferior se ha desarrollado una intensa karstificación, constituyéndose como la principal formación acuífera, con espesores que oscilan entre los $30 \mathrm{y}$ $120 \mathrm{~m}$. La potencia de los materiales aumenta hacia el Este, con alternancia de niveles de limolitas calcáreas y margas. Las margas se localizan predominantemente en la parte occidental, justo lo contrario de lo que ocurre con las calizas (García Rodríguez, 1996).

\section{Geomorfología}

Entre los rasgos geomorfológicos que podemos reseñar, destaca la importante presencia de costras calcáreas, los procesos de karstificación y el endorreísmo. Las costras calcáreas forman la superficie de erosión más antigua, mostrando a su vez karstificación.

El karst es uno de los elementos principales del paisaje, donde cabe señalar la importante presencia de dolinas, con formas circulares o semicirculares, y diámetros considerables; que llegan a ser superiores a los 100 metros en algunos casos, y notables profundidades (García Rodríguez, 1996). Es precisamente a favor de estas estructuras, en las que el nivel piezométrico cortaba la superficie topográfica, donde se formaron un amplio complejo de lagunas, destacando, en la zona de estudio, las de Daimiel y Villarrubia de los Ojos, aunque cabe mencionar el hecho de que aunque estas lagunas estaban alimentadas por el agua subterránea, durante la época estival; la importante evaporación provocaba que algunas de ellas se secaran completamente (García Rodríguez y Llamas, 1993).

Otra característica de la cuenca alta del Guadiana es la formación de turberas, constituidas por suelos con importante contenido en materia orgánica, que como resultado del descenso del nivel freático, entraron en combustión a los largo del cauce del río Guadiana y, haciendo mención a lo que apuntan García Rodríguez y Llamas (1993), este proceso ha dado lugar, entre otros, a dos importantes cambios geomorfológicos, medioambientales y paisajísticos, relacionados directamente con el objeto de estudio del presente trabajo. El primero de ellos sería, la subsidencia generalizada del terreno, a lo largo de una gran extensión superficial, como resultado de la pérdida del agua presente en los poros y la posterior combustión.

Por otro lado, el segundo proceso, sería la formación de colapsos del terreno. Estos tienen una distribución espacial irregular, condicionada por la geometría de los cuerpos sedimentarios. El importante descenso de los niveles piezométricos y la aportación del oxígeno del aire, ha favorecido su oxidación. Las entradas de aire a esta zona subsuperficial se producen probablemente a través de conductos kársticos (secos) y otros tipos de respiraderos internos de los depósitos 
cuaternarios, que pueden tener cierta relación con la porosidad de la propia turba. Los últimos incendios se produjeron durante el otoño del año 2009.

\section{Localización de los colapsos del terreno}

Los colapsos del terreno se han producido únicamente en la MASb Mancha Occidental I, debido a que es la masa con una piezometría más cercana a la superficie y a que, además, presenta una importante karstificación. De este modo, como se puede ver en otros estudios (Gutiérrez, 2004), cuando el peso de los materiales suspendidos sobre las cavidades (costras calcáreas, materiales detríticos, eólicos...) supera su resistencia mecánica, se produce el colapso que se manifiesta en superficie como un agujero con forma circular o semicircular.

En total se han identificado y georreferenciado 34 colapsos. La gran mayoría se encuentran en los municipios de Villarrubia de los Ojos y Daimiel. Un total de 25 colapsos se encontraban documentados antes de comenzar la presente investigación, mientras que los 9 restantes han sido identificados en trabajos de campo relacionados con la elaboración de este artículo, tal y como se muestra en la figura 5 . La inmensa mayoría de los colapsos se localizan en zonas cercanas al cauce del río Guadiana, así como en las lagunas situadas al noroeste de Daimiel; es precisamente en esta zona donde se puede apreciar lo que parece ser una alineación entre colapsos del terreno, que podrían estar marcando en superficie la dirección de un conducto kárstico preferencial en profundidad, tal vez condicionado por una falla normal.

Los colapsos suelen aparecer en material calcáreo, que está cubierto por los materiales cuaternarios de los ríos (limos, arcillas y sobre todo materia orgánica), como ocurre en la mayor parte de los colapsos localizados en el río Guadiana, por lo que es difícil apreciar estrías de arrastre en las paredes del

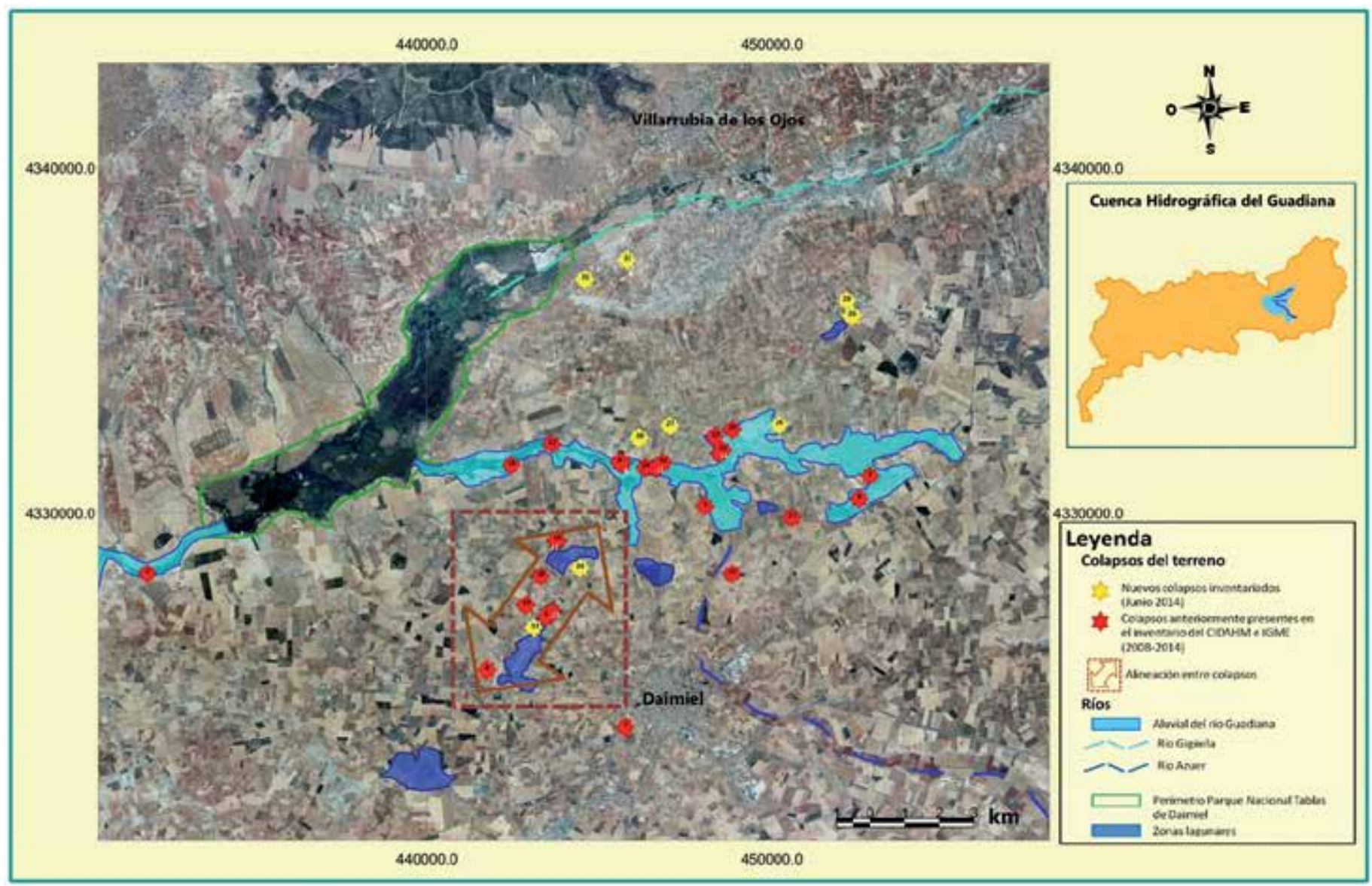

Figura 5. Mapa de localización de colapsos del terreno en la MASb Mancha Occidental I (enero 2015). Ortofotografía aérea del PNOA, CNIG (ING).

Figure 5. Location map of collapses in the field in the grounwater body Mancha Occidental I (January 2005). Orthophotograph of PNOA, CNIG (IGN). 
Bórnez Mejías, K., et al., 2017. Inventario, clasificación y génesis de los colapsos del... Boletín Geológico y Minero, 128 (1): $43-68$

colapso. Además, son muy pocos los que actualmente están totalmente visibles, tal y como se muestra en la tabla 1, ya que la mayoría, al poco tiempo de producirse, se rellenan de escombros por parte de los habitantes de la zona, con el objetivo de evitar la caída de personas y maquinaria agrícola.

\section{Frecuencia, evolución en el tiempo y estado actual}

La manifestación de este tipo de fenómeno presenta tres fases: una primera que tuvo lugar entre el invierno de 2009/10 y la primavera de 2010, momento en que se produjeron la mayor parte de ellos; una segunda fase que abarca entre el invierno de 2010/11 y la primavera de $2011 \mathrm{y}$, finalmente, una tercera correspondiente al invierno 2012/13 y la primavera de 2013, en la que se producen algunos nuevos colapsos.

Para sistematizar la información se ha elaborado la tabla 1, donde aparecen los colapsos con el nombre del paraje en el que se encuentran, año del que datan, estado actual y coordenadas (tomando como referencia el centro del colapso) en sistema ETRS89, proyección UTM Huso 30 (25830).

Del total de colapsos inventariados se tiene constancia que 18 se produjeron en 2010. En el año 2011 aparecieron cuatro nuevos colapsos, al igual que en el año 2013. Otros tres colapsos están constatados en el año 1997 y, por tanto, no relacionados con la actual situación hidrodinámica. Por último, de los cinco colapsos restantes, no se tienen datos acerca de la fecha concreta del hundimiento.

\section{Determinación de alineaciones entre colapsos}

La zona donde se observa de una forma nítida la existencia de una alineación de colapsos es en la parte occidental de la laguna de la Albuera y en El Escoplillo (Daimiel), donde se encuentra la presencia de ocho colapsos, seis de los cuales datan de la primavera de 2010 y los dos restantes de 2013. Posiblemente, en esta zona tenga lugar la existencia de conductos kársticos preferenciales, condicionados por fallas normales, que están conectados, y a través de los cuales se dirigen los flujos más rápidos de agua subterránea. La alineación de colapsos tendría una dirección suroeste-noreste.

\section{Características geomorfológicas de los colapsos}

Para conocer algunas características geomorfológicas de los colapsos, como la dimensión o la dirección preferencial, se llevó a cabo un intenso trabajo de campo que, en la mayor parte de los casos, consistió en realizar una visita a cada uno de los puntos inventariados y determinar sus dimensiones en dos direcciones. La primera medida se realizaba de Este a Oeste y la segunda de Norte a Sur, de tal forma que se tuviera una misma referencia en todos los casos (tabla 2).

Debido a la peligrosidad de la zona de hundimientos, a las grandes dimensiones de algunos colapsos y a la carencia de instrumental de medición a distancia, hubo algunos colapsos en los que la medición no se realizó en el sitio exacto de ubicación en el terreno, sino que se utilizaron imágenes de satélite y visores geográficos digitales para determinar sus dimensiones.

En otros casos, la medición no fue posible de ninguna de estas formas, en concreto en algunos de los colapsos que se encuentran dentro del río Guadiana, debido a que en el momento de llevar a cabo los trabajos de campo, la vegetación y la propia lámina de agua impedían tanto la medición en campo como desde las imágenes de satélite.

En base a estas medidas se ha calculado la media y la mediana, obteniendo unos resultados cuanto menos interesantes. En el caso del conjunto de colapsos encontramos que existe un diámetro medio de 9,8 metros (medido de Norte a Sur) y 9,3 metros (medido de Este a Oeste), incluyendo aquellos colapsos de los que no se conoce la fecha exacta de aparición. En cuanto a las dimensiones según el año del colapso, se ha podido comprobar que aquellos producidos en el año 2010 tienen un diámetro medio superior a los 10 metros, mayor que los producidos posteriormente. Estos colapsos se produjeron en el momento en que el nivel piezométrico se encontraba a mayor profundidad, lo que puede dar la idea de que el karst, en profundidad, se encuentra más desarrollado que en la zona más superficial, por presentar conductos mayores. En este sentido, los colapsos producidos en el año 2011 tienen unas dimensiones medias de 7,25 metros (Norte a Sur) y 6,95 metros (Este a Oeste) de diámetro. Los colapsos acaecidos en el año 2013 tienen un diámetro medio de 5,2 metros (Norte a Sur) y 5,3 metros (Este a Oeste).

En cuanto a la morfología, tienden generalmente a la circular, aunque observando en detalle las medidas de cada uno de ellos se ha comprobado que no en todos los casos son completamente circulares, sino que marcan cierta dirección (colapsos elipsoidales). En la mayor parte de los casos, esta dirección se puede atribuir a la dirección de los flujos subterráneos a través de los conductos kársticos y, por lo tanto, a las direcciones estructurales preferentes. 
Bórnez Mejías, K., et al., 2017. Inventario, clasificación y génesis de los colapsos del... Boletín Geológico y Minero, 128 (1): $43-68$

\begin{tabular}{|c|c|c|c|c|c|c|}
\hline $\begin{array}{c}\text { Colapsos } \\
\text { inventariados }\end{array}$ & Paraje & Año & $\begin{array}{c}\text { Cota } \\
\text { (m s.n.m.) }\end{array}$ & $\begin{array}{c}\text { Coordenada } \\
\text { X }\end{array}$ & $\begin{array}{c}\text { Coordenada } \\
Y\end{array}$ & Estado actual \\
\hline 1 & Toriles & 2010 & 611 & 452859.89 & 4331083.16 & Visible con agua \\
\hline 2 & Presa Puente Navarro & 1997 & 604 & 431893.42 & 4328250.08 & Visible con escombros \\
\hline 3 & Albuera 1 & 2010 & 614 & 443445.34 & 4327006.81 & No visible \\
\hline 4 & Ardales & 2010 & 617 & 441740.41 & 4325455.40 & Visible \\
\hline 5 & Camino de la Máquina & 2010 & 617 & 447957.34 & 4330412.96 & *ND \\
\hline 6 & Navaseca & 2010 & 611 & 445669.02 & 4331439.43 & Cubierto de agua \\
\hline 7 & Camino CR & 2013 & 621 & 445759.18 & 4323787.86 & No visible \\
\hline 8 & Sordico & 2011 & 616 & 452725.15 & 4330276 & Visible con escombros \\
\hline 9 & EI Nuevo & 2010 & 614 & 445583.42 & 4331468.67 & Cubierto de agua \\
\hline 10 & Escoplillo 1 & 2013 & 616 & 443768.35 & 4329230.33 & Visible con escombros \\
\hline 11 & Escoplillo 2 & 2013 & 616 & 443744.72 & 4329190.45 & Visible con escombros \\
\hline 12 & Griñón & 2010 & 612 & 443905.70 & 4331879.54 & No visible \\
\hline 13 & Máquina 1 & ${ }^{*} \mathrm{SF}$ & 615 & 448345.38 & 4332216.22 & Visible \\
\hline 14 & Máquina 2 & ${ }^{*} \mathrm{SF}$ & 613 & 448488.05 & 4331719.75 & Visible \\
\hline 15 & Máquina 3 & ${ }^{*} \mathrm{SF}$ & 613 & 448585.06 & 4331833.88 & Visible \\
\hline 16 & Molemocho & 1997 & 606 & 442450.53 & 4331388.77 & No visible \\
\hline 17 & Moralillo & 2013 & 622 & 450588.05 & 4329876.54 & Cubierto con escombros \\
\hline 18 & Quintanar & 2010 & 619 & 443294.69 & 4328176.12 & Visible con escombros \\
\hline 19 & Vereda Puente Navarro & 2010 & 621 & 442867.68 & 4327337.37 & No visible \\
\hline 20 & El Nuevo & 1997 & 612 & 446342.39 & 4331331.71 & No visible \\
\hline 21 & Nuevo-Máquina & ${ }^{*} \mathrm{SF}$ & 609 & 446633.42 & 4331308.88 & No visible \\
\hline 22 & La Gramosa & 2010 & 622 & 448858.97 & 4328244.47 & Visible con escombros \\
\hline 23 & Albuera 2 & 2010 & 619 & 443638.93 & 4327134.83 & No visible \\
\hline 24 & Parrilla & 2010 & 612 & 446844.56 & 4331462.96 & No visible \\
\hline 25 & Camino Moledores & 2010 & 612 & 448858.97 & 4332415.95 & No visible \\
\hline 26 & Castañares 1 & 2011 & 626 & 452331.95 & 4335718.57 & Visible \\
\hline 27 & ElTallar & *SF & 627 & 447055.17 & 4332525.60 & Visible \\
\hline 28 & Castañares 2 & 2011 & 627 & 452184 & 4336161 & Visible \\
\hline 29 & Zuacorta & 2011 & 614 & 450217 & 4332558 & Visible con escombros \\
\hline 30 & El Chaparral & 2010 & 622 & 446167 & 4332180 & Visible con escombros \\
\hline 31 & Camino La Rinconada & 2010 & 610 & 444577 & 4336772 & No visible \\
\hline 32 & Camino Griñón & 2010 & 612 & 445800 & 4337332 & No visible \\
\hline 33 & Pedrizas & 2010 & 613 & 443107.39 & 4326672.53 & Escombros \\
\hline 34 & Albillares & 2010 & 616 & 444439.43 & 4328410.22 & Escombros \\
\hline
\end{tabular}

*SF: No se conoce la fecha de aparición $\quad$ *ND: No hay datos

*SF: The date of appearance is not known *ND: There are not data

Tabla 1. Datos de identificación, localización y caracterización de los colapsos (agosto 2014).

Table 1. Data for the identification, localization and characterization of the collapses (August 2014). 


\section{Origen de los colapsos en relación a la evolución hi- drogeológica de la zona}

A la hora de establecer una hipótesis acerca del origen de los colapsos del terreno, se consideró oportuno tener en cuenta, en primer lugar, la calidad química del agua. El motivo era analizar si el origen de los hundimientos estaba directamente relacionado con la disolución actual de carbonatos. Por este motivo, se realizó un estudio de los parámetros químicos en muestras tomadas en sondeos de la Confederación Hidrográfica del Guadiana, cercanos a los colapsos. Con estos datos, y teniendo en cuenta la fecha en la que se han producido, se podrían identificar cambios en la composición química del agua que fueran determinantes en el origen del colapso.

Los resultados obtenidos reflejan una aparente carencia de relación entre la distribución de los principales parámetros químicos del agua $\left(\mathrm{SO}_{4}{ }^{\prime}, \mathrm{HCO}_{3}{ }^{-}\right.$, $\left.\mathrm{Ca}^{2+}, \mathrm{Cl}^{-} ..\right)$, y la aparición de los colapsos del terreno, ya que no se observaron variaciones apreciables en las concentraciones iónicas del agua durante los años en que se produjeron los hundimientos.

Una vez descartado este posible origen, se buscó la causa de los colapsos en las variaciones rápidas de los niveles piezométricos.

En este sentido, algunos autores han tratado de describir este tipo de fenómenos diferenciándolos en dos tipologías (Aley et al., 1972). Por un lado, los colapsos originados por los descensos piezométricos $y$, en segundo lugar, los causados por el ascenso piezométrico, que sería el que aparece representado en la zona de estudio.

En el primero de los casos, el proceso tendría lugar a raíz de la extracción de aguas subterráneas, por actividades agrícolas o por actividades mineras. La extracción de agua provoca el vaciado de las cavidades. Este proceso genera, en cierto modo, una presión negativa en la cavidad conforme el nivel va descendiendo, lo que produce que el recubrimiento superior, tanto del techo como de las paredes, se vean afectados. Si este proceso continua, puede existir una propagación de la cavidad hacia superficie, hasta que el terreno colapsa debido a la inconsistencia del mismo. Esto es lo que viene ocurriendo durante décadas en amplias zonas de China, Estados Unidos y Sudáfrica. En el caso de China, este fenómeno se ha convertido en uno de sus principales problemas geológicos (Keqiang et al., 2010).

En España no son frecuentes los colapsos relacionados con la sobreexplotación, aunque se tiene conocimiento de la presencia de este fenómeno en zonas situadas al noroeste de la región de Murcia y en algunas áreas del valle del Ebro (Andreu et al., 2004).
En segundo lugar, aparecen los colapsos originados por ascensos piezométricos, tal es el caso de los ocurridos en la MASb Mancha Occidental I, en una zona en la que durante décadas ha existido una intensa explotación de los recursos hídricos subterráneos, con importantes descensos piezométricos. Cuando los niveles ascienden de manera rápida debido a secuencias climáticas húmedas $\mathrm{y} / \mathrm{o}$ a un menor volumen de extracción, es el propio proceso de recirculación del agua por conductos kársticos antiguos, lo que provoca la limpieza de los mismos que, tras llevar décadas sin funcionar, se encuentran obstruidos por pequeños derrumbes del material del techo y las paredes laterales. Del mismo modo que el agua circula por grandes galerías, también lo hace por otras de menor tamaño, provocando cierta inestabilidad en el terreno y pudiendo dar lugar al colapso.

Al igual que se analizaron datos de la calidad química del agua en puntos cercanos a los colapsos, también se buscaron puntos piezométricos que estuvieran cercanos a éstos, y de los que se tuviera una serie temporal de datos suficientemente amplia para obtener conclusiones válidas. Uno de los ejemplos es el representado en la figura 6, correspondiente al punto piezométrico 04.04.253 de la base de datos de la $\mathrm{CHG}$, en el que se observa una ligera tendencia al descenso del nivel piezométrico hasta comienzos de 2010. También se aprecian claramente las oscilaciones estacionales. A partir de 2010 se produce un brusco ascenso del nivel piezométrico que, en tan solo un año y medio, se recupera en este punto más de 15 metros. Evoluciones similares se han observado en el resto de los casos estudiados.

A tan sólo 800 metros de este piezómetro, en dirección noroeste, nos encontramos con el colapso

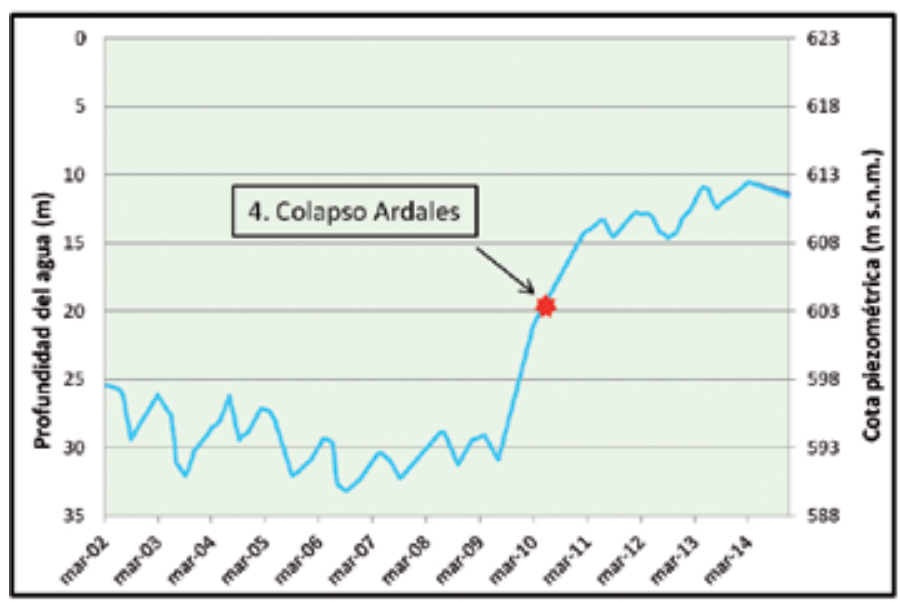

Figura 6. Evolución piezométrica en el punto 04.04.253 (marzo 2002 a diciembre 2014), (datos CHG, 2014).

Figure 6. Piezometric evolution in point 04.04.253 (March 2002 to December 2014), (data CHG, 2014). 
Bórnez Mejías, K., et al., 2017. Inventario, clasificación y génesis de los colapsos del... Boletín Geológico y Minero, 128 (1): $43-68$

\begin{tabular}{|c|c|c|c|c|c|}
\hline $\begin{array}{c}\text { Colapsos } \\
\text { inventariados }\end{array}$ & Paraje & $\begin{array}{c}\text { *Dimensiones } \\
(\mathrm{m})\end{array}$ & Dirección & $\begin{array}{l}\text { Profundidad c } \\
\text { según las isop } \\
\text { Año del colapso }\end{array}$ & $\begin{array}{l}\text { el agua } \\
\text { ezas (m) } \\
\text { Año } 2014\end{array}$ \\
\hline 1 & Toriles & $20.75 \times 19.92$ & Sur- norte & 11 & 1 \\
\hline 2 & Presa Puente Navarro & $9 \times 9.05$ & Circular & *ND & 2 \\
\hline 3 & Albuera 1 & $11.40 \times 10.75$ & Sureste-noroeste & 10 & 7 \\
\hline 4 & Ardales & $8 \times 9.30$ & Sureste-noroeste & 18 & 11 \\
\hline 5 & Camino de la Máquina & $10.15 \times 9$ & Sureste-noroeste & 18 & 10 \\
\hline 6 & Navaseca & *ND & *ND & 11 & 5 \\
\hline 7 & Camino CR & *ND & *ND & 10.5 & 9.4 \\
\hline 8 & Sordico & $5 \times 5$ & Circular & 8 & 4 \\
\hline 9 & El Nuevo & *ND & ${ }^{*} \mathrm{ND}$ & 14 & 8.5 \\
\hline 10 & Escoplillo 1 & $6 \times 6$ & Circular & 5.5 & 8 \\
\hline 11 & Escoplillo 2 & *ND & *ND & 5.5 & 8 \\
\hline 12 & Griñón & $23 \times 17$ & Noroeste-sureste & 8 & 6 \\
\hline 13 & Máquina 1 & $9.96 \times 9.83$ & Circular & ${ }^{*} \mathrm{ND}$ & 7 \\
\hline 14 & Máquina 2 & $7.23 \times 7.29$ & Circular & *ND & 5 \\
\hline 15 & Máquina 3 & $8.39 \times 8.35$ & Circular & ${ }^{*} \mathrm{ND}$ & 5 \\
\hline 16 & Molemocho & $20 \times 18$ & Sureste-noroeste & *ND & 1.8 \\
\hline 17 & Moralillo & $3.70 \times 4.14$ & Sur- norte & 11 & 12 \\
\hline 18 & Quintanar & $10.5 \times 8.66$ & Sureste-noroeste & 15 & 10.5 \\
\hline 19 & Vereda Puente Navarro & $5 \times 5$ & Circular & 19 & 13 \\
\hline 20 & El Nuevo & *ND & *ND & ${ }^{*} \mathrm{ND}$ & 5 \\
\hline 21 & Nuevo-Máquina & $9 \times 9$ & Circular & *ND & 3 \\
\hline 22 & La Gramosa & *ND & ${ }^{*} \mathrm{ND}$ & 18 & 12 \\
\hline 23 & Albuera 2 & $11.62 \times 10.5$ & Este-oeste & 10 & 11 \\
\hline 24 & Parrilla & $4 \times 4.7$ & Circular & 14 & 3.1 \\
\hline 25 & Camino Moledores & $6.9 \times 7$ & Circular & 14 & 6 \\
\hline 26 & Castañares 1 & $8.70 \times 8.71$ & Circular & 21 & 14.5 \\
\hline 27 & ElTallar & $16 \times 14.11$ & Noroeste-sureste & ${ }^{*} \mathrm{ND}$ & 19 \\
\hline 28 & Castañares 2 & $7.26 \times 8.63$ & Norte-sur & 22 & 16 \\
\hline 29 & Zuacorta & $8.07 \times 5.47$ & Noreste-suroeste & 8 & 5 \\
\hline 30 & El Chaparral & $13.28 \times 16.23$ & Norte-sur & 22 & 13 \\
\hline 31 & Camino La Rinconada & *ND & *ND & 4 & 4 \\
\hline 32 & Camino Griñón & *ND & ${ }^{*} \mathrm{ND}$ & 6 & 6 \\
\hline 33 & Pedrizas & $9.21 \times 9.48$ & Sureste-noroeste & 11 & 6.5 \\
\hline 34 & Albillares & $7.9 \times 6.37$ & Suroeste- noreste & 11 & 6.53 \\
\hline
\end{tabular}

*ND: No hay datos

*ND: There are not data
* Dimensiones: Hace referencia a las medidas tomadas de norte a sur frente a las medidas este-oeste

* Dimensions: Refers to the averages taken from North to South across the East-West measures

Tabla 2. Diámetros, dirección y profundidad del agua en cada uno de los colapsos.

Table 2. Diameters, direction and water depth in the collapses. 
4 (Ardales). Si se compara la fecha del hundimiento con la evolución piezométrica se puede establecer en el gráfico, de una forma bastante precisa, el momento en que colapsó el terreno. En este sentido se ha comprobado que los colapsos se producen en aquellos años en los que el ascenso piezométrico es más brusco y rápido, tal es el caso de 2010, 2011 y 2013.

Para analizar en profundidad la evolución piezométrica de los últimos años, se han elaborado una serie de mapas de isopiezas muy detallados, entre los años 2009 y 2014 (figuras 7 y 8). En el año 2009 la MASb se encontraba en una situación crítica, con la presencia de una amplia depresión piezométrica que se extendía hasta el límite occidental de la MASb Mancha Occidental II. Los ríos se comportaban como influentes con respecto al flujo subterráneo. La cota piezométrica se encontraba en el entorno de los Ojos del Guadiana a una profundidad de unos 36 metros. En el invierno de 2009 a 2010 comienza un periodo húmedo con abundantes e intensas precipitaciones, y la MASb en el periodo 2009-2011 recupera una media de 12 metros (Mejías et al., 2012a). Los colapsos

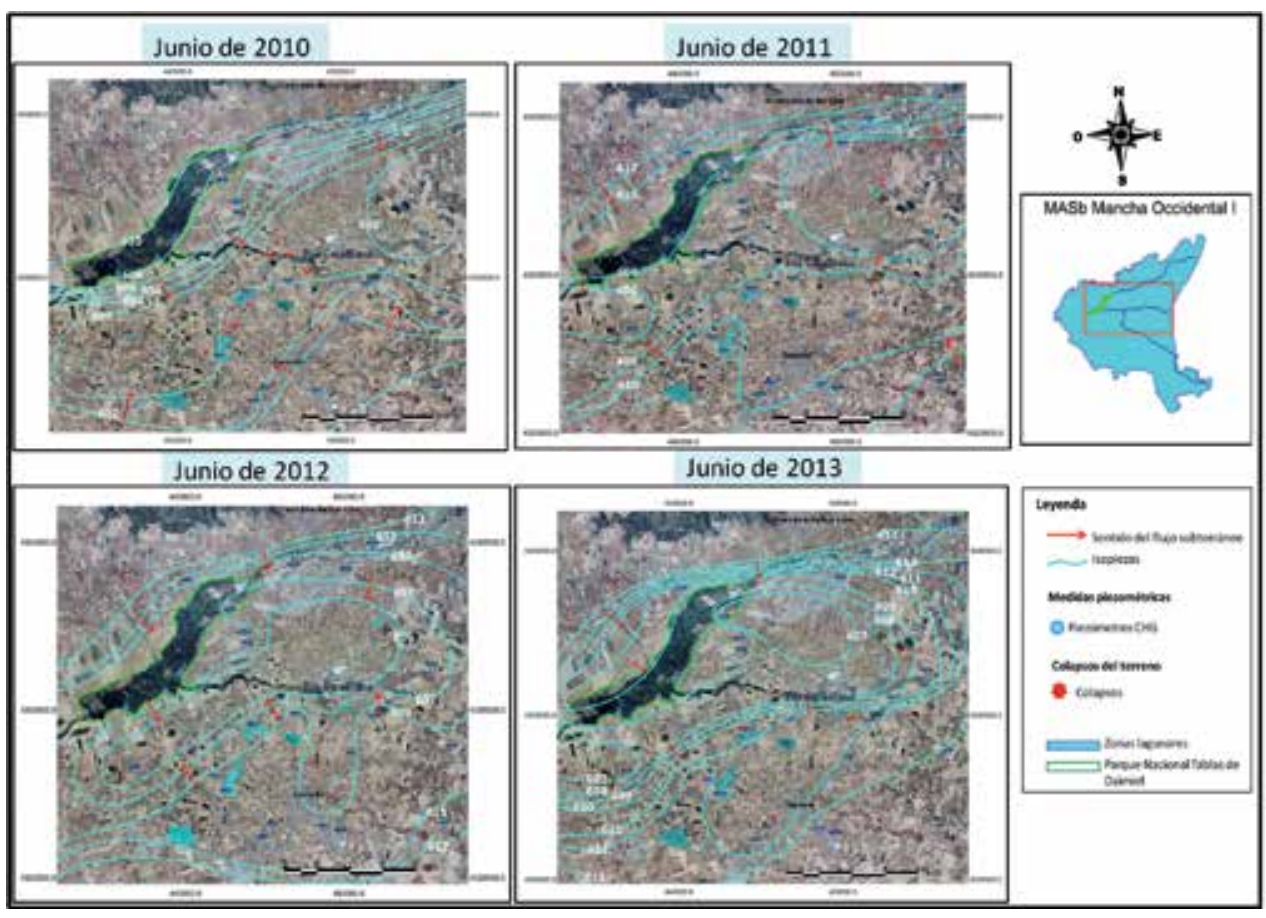

Figura 7. Mapas de isopiezas en la zona de estudio entre los años 2010 y 2013 (datos del IGME y la CHG), Ortofotografía del PNOA, CNIG (IGN). Figure 7. Isopiezas maps in the study area between 2010 and 2013 (data of IGME and CHG, Orthophotograph of PNOA, CNIG (IGN).
Figura 8. Mapa de isopiezas de la zona de estudio en julio de 2014 (datos IGME y $\mathrm{CHG}$ ). Ortofotografía del PNOA, CNIG (IGN).

Figure 8. Isopiezas map of study area in july 2014. (data IGME and CHG). Orthophotograph of PNOA, CNIG (IGN).

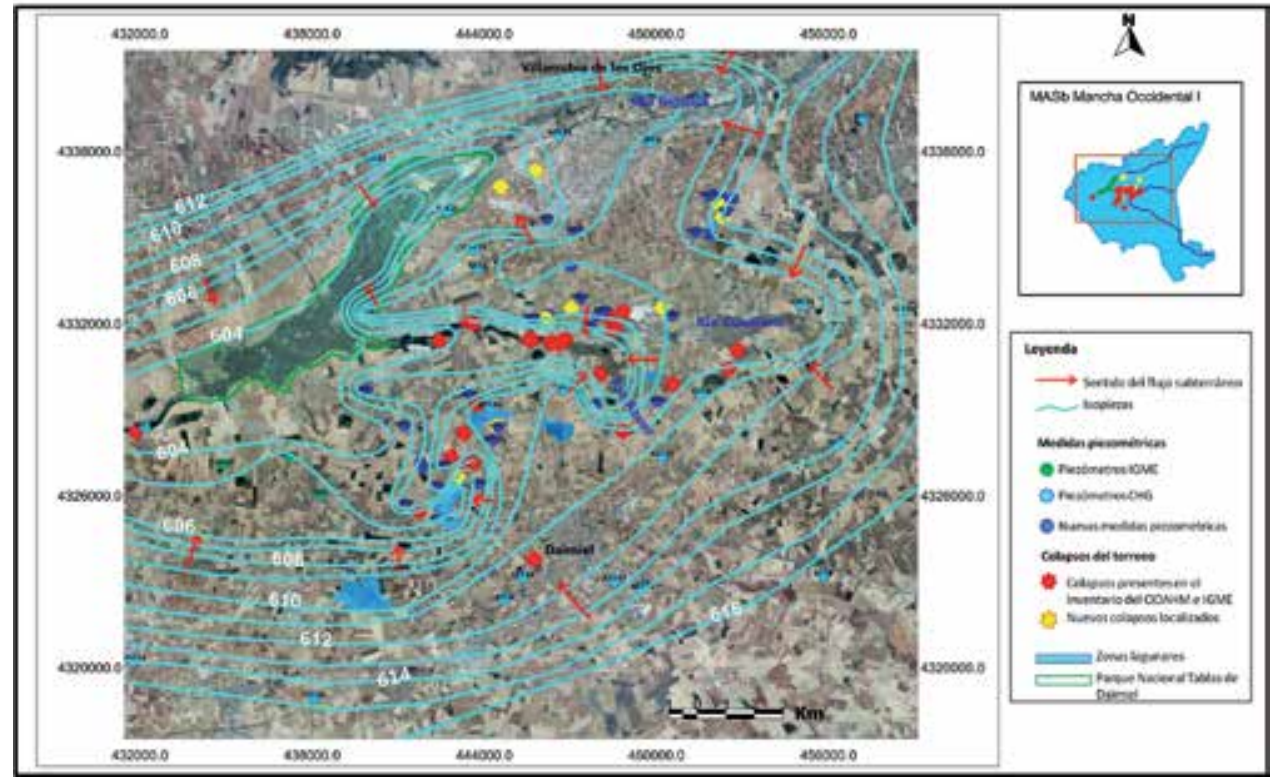


que se producen durante este año lo hacen en la zona central y occidental del área de estudio. Es el año en que se producen más colapsos, debido a que el ascenso es muy brusco.

Durante el año 2011 los colapsos producidos se desplazan hacia la zona central y este. En el año 2012 lo más importante es que se produce un ascenso piezométrico que avanza de forma progresiva hacia el Oeste. Es un año seco, y no se producen colapsos.

Durante el año 2013, la cota piezométrica sigue ascendiendo. Todos los colapsos en este periodo se producen en zonas cercanas a lagunas.

En el año 2014, se ha elaborado una piezometría detallada a partir de la base de datos de puntos de agua del IGME, los piezómetros de la CHG, así como 30 nuevas medidas realizadas alrededor de los colapsos. Destaca un notable ascenso piezométrico que provoca que los flujos subterráneos se dirijan hacia el Parque Nacional de las Tablas de Daimiel, que al estar en la zona topográfica más baja, da lugar a que el nivel freático corte la superficie. Este hecho no sucedía desde 1983, año en el que existían surgencias de agua subterránea en algunas zonas del cauce del río Guadiana.

Se han podido cuantificar las salidas de agua subterránea al cauce del río Guadiana entre el Molino de la Máquina y el Nuevo. En enero de 2016 el aporte de agua subterránea en el tramo del río mencionado era de $295 \mathrm{~L} / \mathrm{s}$; el máximo aporte subterráneo se produjo en mayo de 2014 con 650 L/s (Mejías, 2015).

En cuanto a las lagunas, que son una de las zonas donde mayor índice de colapsos se pueden encontrar, en algunos casos actúan como zona de recarga y en otros lo hacen como zona de descarga (Albuera).

Por tanto, en el proceso de formación de los colapsos cabría tener en cuenta dos fases. En primer lugar la fase de descenso del nivel piezométrico, motivado por la sequía y la sobreexplotación del acuífero. Esta situación provocó un vaciado que dejó grandes huecos en el subsuelo. Durante esta fase de descenso es muy probable que las rocas carbonatadas se resquebrajaran. Posteriormente se produce una segunda fase, en este caso de ascenso piezométrico, lo que provocaría que parte del techo y paredes de las cavidades kársticas comenzaran a caer mediante sucesivos desplomes, favorecidos en la mayor parte de los casos por grietas de descarga y más notoriamente por el arrastre del agua en circulación. De tal forma que si el peso de los materiales suspendidos sobre la cavidad (costras calcáreas, materiales detríticos, eólicos...) supera a su resistencia mecánica, se produce el colapso, manifestándose en superficie como un agujero de forma circular o elipsoidal.

\section{Tipología de los colapsos}

Partiendo del análisis de las características hidrológicas, geomorfológicas y geológicas de la zona de estudio, se realizó una clasificación de tipologías de colapsos, de acuerdo a sus características estructurales, génesis y profundidad del nivel piezométrico en el momento de colapso.

En conjunto, se han diferenciado cuatro tipos de colapsos: colapsos aluviales, colapsos en zonas de dolina, colapsos lagunares y colapsos de tipo intermedio; en algunos de los cuales aparecen varios subgrupos.

Esta clasificación aparece reflejada en la tabla 3. Un elemento muy importante, a la hora de realizar la clasificación, ha sido la aproximación de la profundidad piezométrica en el momento del colapso (tabla 2), que ha sido fundamental su clasificación. En este sentido, y según el criterio aplicado, se parte de la base que aquellos colapsos en los que la profundidad del agua subterránea era igual o inferior a 11 metros fueron provocados por flujos predominantemente horizontales, todos ellos de tipo aluvial y lagunar. En cambio, cuando la profundidad del agua supera los 11 metros, comienzan a actuar los flujos verticales, aunque este segundo grupo es variable y está en función de la presencia o ausencia de dolinas.

Dentro de esta clasificación aparece una particularidad: el caso de los colapsos aluviales provocados por la autocombustión de la turba, que en cierto modo no dependen estrictamente de las variaciones del nivel piezométrico.

\section{Colapsos aluviales}

Por colapsos aluviales se han clasificado todos aquellos que se han producido bien a lo largo del cauce de alguno de los ríos que confluyen en el Parque Nacional de las Tablas de Daimiel, bien porque se sitúan muy cercanos a los cauces de estos ríos y tienen relación con los mismos (figura 9). Suponen un total de 16 colapsos del conjunto de 34, constituyéndose como la tipología más numerosa.

De estos, no todos tienen las mismas características, ya que el origen de algunos está directamente relacionado con los flujos subhorizontales de descarga/recarga, donde los sedimentos aluviales de los cursos fluviales podrían haber tenido un importante papel, mientras que el resto tiene su principal origen en la autocombustión de la turba, presente principalmente en el cauce del río Guadiana. Esto se debe a que la materia orgánica, principalmente de origen vegetal, se ha ido acumulando a lo largo miles de años 
Bórnez Mejías, K., et al., 2017. Inventario, clasificación y génesis de los colapsos del... Boletín Geológico y Minero, 128 (1): $43-68$

\begin{tabular}{|c|c|c|c|c|c|c|}
\hline \multirow[b]{2}{*}{$\mathbf{N}^{\circ}$ ID } & \multirow[b]{2}{*}{ Paraje } & \multicolumn{2}{|c|}{ Colapsos Aluviales } & \multirow{2}{*}{$\begin{array}{c}\begin{array}{c}\text { Colapsos en } \\
\text { dolinas }\end{array} \\
\begin{array}{c}\text { Flujos } \\
\text { verticales }\end{array}\end{array}$} & \multirow{2}{*}{\begin{tabular}{|c|}
$\begin{array}{c}\text { Colapsos } \\
\text { lagunares }\end{array}$ \\
$\begin{array}{l}\text { Flujos horizontales } \\
\text { en zona de recarga }\end{array}$ \\
\end{tabular}} & \multirow{2}{*}{$\begin{array}{c}\begin{array}{c}\text { Colapsos de tipo } \\
\text { intermedio }\end{array} \\
\begin{array}{c}\text { Flujos verticales y } \\
\text { horizontales }\end{array}\end{array}$} \\
\hline & & Turbas & $\begin{array}{c}\text { Flujos } \\
\text { horizontales } \\
\text { de descarga }\end{array}$ & & & \\
\hline 1 & Toriles & & $x$ & & & \\
\hline 2 & Presa Puente Navarro & $x$ & & & & \\
\hline 3 & Albuera 1 & & & & $x$ & \\
\hline 4 & Ardales & & & $x$ & & \\
\hline 5 & Camino de la Máquina & & & $x$ & & \\
\hline 6 & Navaseca & & $x$ & & & \\
\hline 7 & Camino CR & & & & $x$ & \\
\hline 8 & Sordico & & & & & $x$ \\
\hline 9 & El Nuevo & $x$ & & & & \\
\hline 10 & Escoplillo 1 & & & & $x$ & \\
\hline 11 & Escoplillo 2 & & & & $\mathrm{x}$ & \\
\hline 12 & Griñón & & $x$ & & & \\
\hline 13 & Máquina 1 & & $x$ & & & \\
\hline 14 & Máquina 2 & & $x$ & & & \\
\hline 15 & Máquina 3 & & $x$ & & & \\
\hline 16 & Molemocho & $x$ & & & & \\
\hline 17 & Moralillo & & & & $x$ & \\
\hline 18 & Quintanar & & & $x$ & & \\
\hline 19 & Vereda Pte Navarro & & & $x$ & & \\
\hline 20 & El Nuevo & $x$ & & & & \\
\hline 21 & Nuevo-Máquina & $x$ & & & & \\
\hline 22 & La Gramosa & & & $x$ & & \\
\hline 23 & Albuera 2 & & & & $x$ & \\
\hline 24 & Parrilla & & $x$ & & & \\
\hline 25 & Camino Moledores & $x$ & & & & \\
\hline 26 & Castañares 1 & & & & & $x$ \\
\hline 27 & ElTallar & & & & & $x$ \\
\hline 28 & Castañares 2 & & & & & $x$ \\
\hline 29 & Zuacorta & & $\mathrm{x}$ & & & \\
\hline 30 & El Chaparral & & & $x$ & & \\
\hline 31 & Camino La Rinconada & & $x$ & & & \\
\hline 32 & Camino Griñón & & $x$ & & & \\
\hline 33 & Pedrizas & & & & $x$ & \\
\hline 34 & Albillares & & & & $x$ & \\
\hline
\end{tabular}

Tabla 3. Clasificación de los colapsos según su tipología.

Table 3. Classification of collapses according to their typology. 


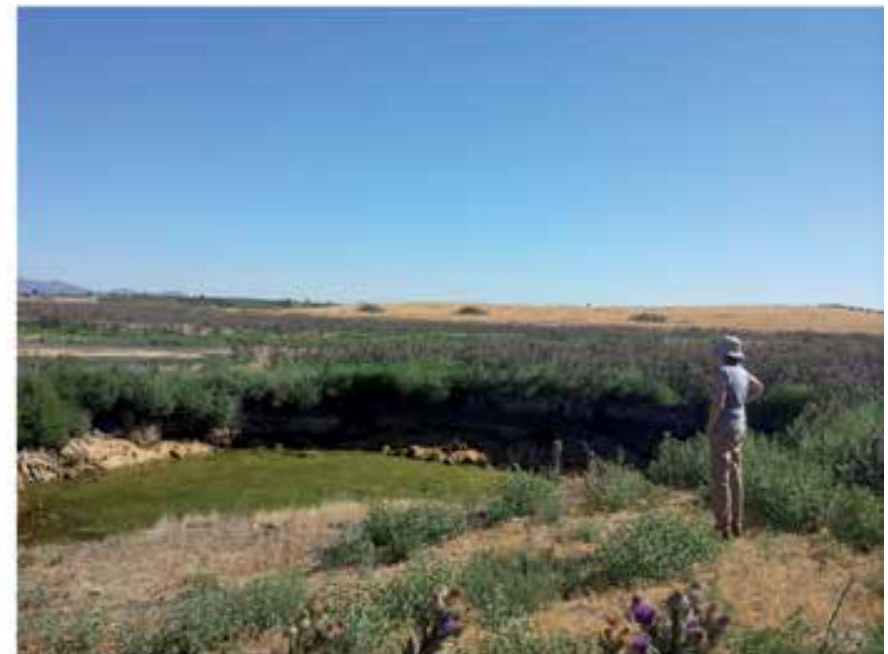

Figura 9. Ejemplo de colapso aluvial ( $\mathrm{n}^{\circ} 1$, Toriles).

Figure 9. Example of alluvial collapse ( $n^{\circ} 1$, Toriles).

en las superficies encharcadas $y$, en situaciones de anoxia, da lugar a la formación de turba. Al secarse el suelo, la turba pierde el agua y por tanto la humedad, por lo que el aire comienza a circular por los huecos y la turba comienza a oxidarse. Se produce así un considerable aumento de la temperatura que, llegando a un cierto umbral, variable en función de los condicionantes medioambientales, da lugar a la autocombustión.

Tal y como se describe en García Rodríguez y Llamas (1992), la autocombustión no es un proceso continuo, sino que presenta una distribución irregular, tanto vertical como horizontalmente. Esto es debido al proceso irregular de sedimentación de los depósitos, y es por ello por lo que el espesor de turba no es simétrico a lo largo de todo el cauce, sino que varía desde unos pocos centímetros a algunos me$\operatorname{tros}(2-3 \mathrm{~m})$.

Las abundantes precipitaciones que han tenido lugar durante el periodo húmedo (2009-2013) (Mejías et al., 2012b) derivaron en una infiltración de agua de lluvia que, en algunos casos, fue muy rápida, tanto por la porosidad propia del terreno, como por los sumideros que se formaron a lo largo del cauce de los ríos. Esto generó una rápida recarga del acuífero, dando lugar a flujos subterráneos verticales ascendentes y subhorizontales que, en la mayor parte de los casos, se dirigían hacia la gran depresión piezométrica de la zona central de la MASb. Estos flujos hídricos contribuyeron, por tanto, a la limpieza de las arcillas de descalcificación y a la reactivación de las cavidades kársticas (disolución). Lo que provocó una inestabilidad en los conductos preferenciales, hasta el punto de no poder soportar el peso de los techos de los conductos y hundirse bruscamente.

En cuanto a los colapsos producidos por la autocombustión de la turba (figura 10), el comportamiento es similar al de los propiamente kársticos, salvo que los huecos en lugar de formarse por los procesos kársticos, ocurridos a lo largo de cientos de años, y reactivados recientemente, se han formado por la combustión de la turba, que dejó grandes huecos más o menos cercanos a la superficie, y que tras humedecerse el terreno y ascender los niveles piezométricos, han dado lugar a colapsos debido a la inestabilidad del terreno.

En este sentido, algunos trabajos precedentes, como García Rodríguez y Llamas (1992), ya apuntaban a que este tipo de colapsos podrían haber aparecido en lugares donde el espesor de turba fuera mayor o quizás por el hundimiento de alguna caverna de origen kárstico. Todo indica la interrelación entre estos elementos como origen de este tipo de colapsos.

También en García Rodríguez (1996) se realizó un estudio de las turberas del Guadiana, elaborando tanto cartografía, como perfiles del terreno (zona de Zuacorta), en los que se puede comprobar las áreas que, en aquel momento, se encontraban sin alterar, así como las que estaban en proceso de autocombustión etc.

En García Rodríguez y Llamas (1992), aparece también un análisis de este tipo, en el que se muestra cartográficamente la evolución de la superficie quemada en las turberas del río Guadiana, y se aprecia que a partir de 1991, empiezan a aparecer, lo que los autores denominan "escarpes de colapso".

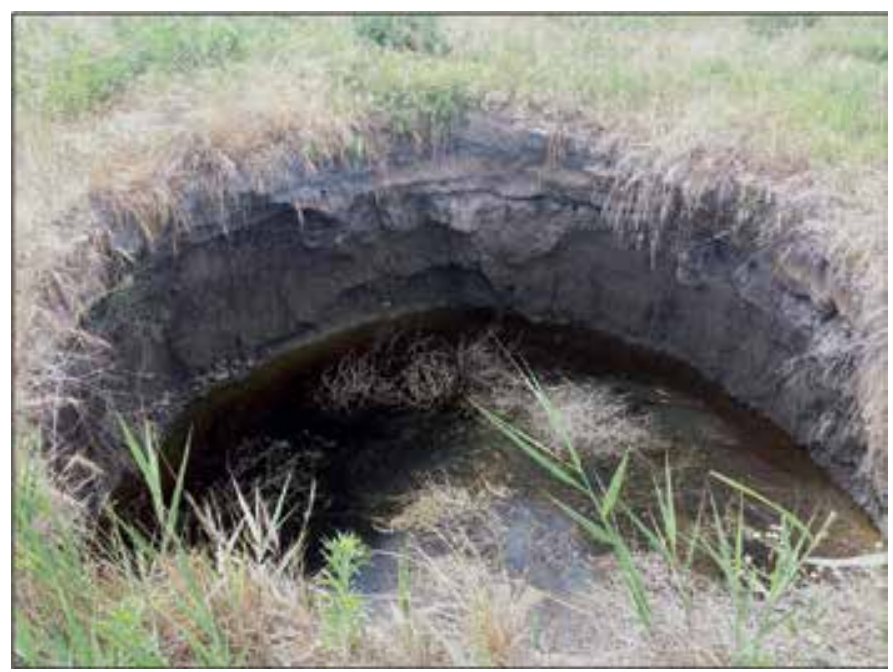

Figura 10. Ejemplo de colapso por combustión de la turba $\left(n^{\circ} 25\right.$, Camino Moledores).

Figure 10. Example of collapse by combustion of peat $\left(n^{\circ} 25\right.$, Camino Moledores). 
Todo ello da muestra de la complejidad del área de estudio, de cara a elaborar una cartografía de susceptibilidad por nuevos colapsos.

\section{Colapsos en zonas de dolinas}

Una segunda tipología hace referencia a los colapsos del terreno que aparecen en el interior de las dolinas, por lo general localizados en los fondos, que es predominantemente hacia donde se dirigen los flujos de agua subsuperficiales. Lo más característico de los colapsos identificados dentro de este grupo, y que los diferencia aún más del resto, es que se producen predominantemente por flujos verticales, y no horizontales. En los colapsos de dolinas encontramos unas profundidades del agua subterránea superiores a los 15 metros en el momento del colapso (tabla 2).

En el inventario de campo realizado, se pudo apreciar que no todos los colapsos que aparecen en las dolinas y/o uvalas tienen las mismas características, sino que la diferencia radica, entre otros aspectos, en el tamaño de la cuenca vertiente de la dolina. En algunos casos, estas superan con creces los 500 metros de diámetro, llegando en ocasiones a formar grupos de dolinas (uvalas), mientras que en otros casos los tamaños son más modestos, superando apenas los 50 metros de diámetro.

Los flujos de agua, tanto superficiales como subterráneos, se han dirigido hacia estas zonas topográficamente deprimidas, provocando hundimientos en los puntos geotécnicamente más débiles.

\section{Colapsos lagunares}

La siguiente tipología hace referencia a aquellos colapsos que han aparecido, bien dentro de lagunas, bien en la periferia de las mismas; tal es el caso del ejemplo de la figura 11, y que han sido provocados por flujos horizontales (profundidad del agua inferior a 11 metros), en aquellos lugares que actuaban, en el año en que se produjo el colapso como zonas de recarga del acuífero, ya que se encuentran en mayor o menor medida descolgadas con respecto al nivel freático.

Al ser zonas más deprimidas, los flujos de agua, sobre todo los subsuperficiales del entorno de las lagunas, se han dirigido hacia éstas. Durante el último periodo húmedo se ha producido una recarga a partir de estas áreas lagunares, donde el nivel piezométrico era somero. La principal diferencia entre esta tipología, con respecto a la anterior, radican en que estas lagunas han sido rebosadero natural del

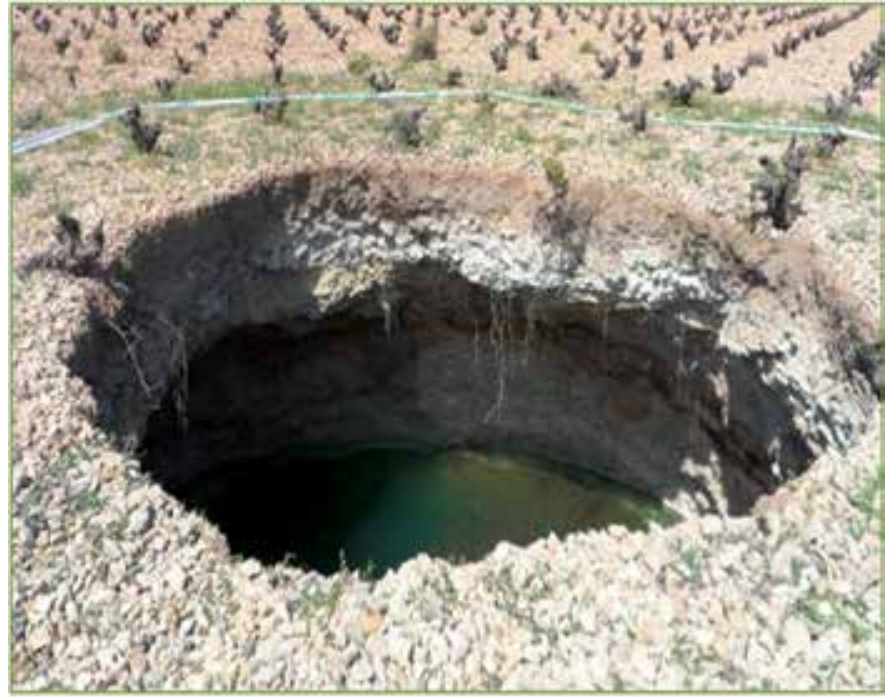

Figura 11. Ejemplo de colapso lagunar ( $\mathrm{n}^{\circ} 10$, Escoplillo). Figure 11. Example of lagoon collapse ( $n^{\circ} 10$, Escoplillo).

acuífero, puesto que el freático cortaba la superficie de las mismas (con anterioridad a la sobreexplotación). En cambio, en las dolinas en las que se han registrado colapsos, el nivel freático es más profundo (entre 15 y 22 metros), y en ningún caso puede cortar a la superficie topográfica, por lo que predominarían los flujos verticales, al contrario que en las lagunas.

\section{Colapsos de tipo intermedio}

Un último grupo de colapsos sería el compuesto por aquellos cuyo origen no resulta tan claro y que, podrían deberse tanto a la presencia de flujos horizontales como verticales, no predominando en principio ninguno de ellos. Esta tipología se da en colapsos que parecen similares a los que se forman en dolinas, debido principalmente a la importante profundidad a la que se encontraba el agua en el momento de producirse el hundimiento, aunque en todos los casos superior a 20 metros, como el mostrado en el ejemplo (figura 12). Lo que diferencia a este tipo de colapsos de los que se producen en las zonas bajas de las dolinas es que no se encuentran en zonas muy deprimidas, en cuencas cerradas, ni tan siquiera en dolinas como en el caso de los colapsos 19, 27 y 28. Además, en gran parte de los casos, estos colapsos son los que presentan un mayor diámetro, como es el caso del colapso número 27 (El Tallar), con un diámetro comprendido entre los 14 y los 16 metros.

Estos colapsos se podrían haber producido tanto por flujos verticales, como por flujos horizontales más profundos. De este modo, se podría atribuir el 


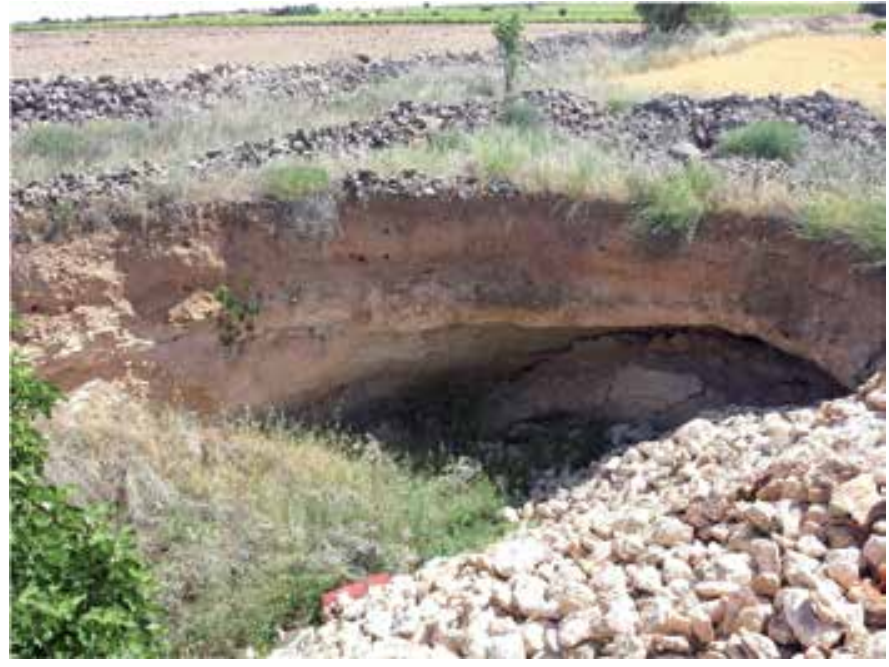

Figura 12. Ejemplo de colapso de tipo intermedio (n²7, ElTallar). Figure 12. Example of collapse of intermediate type ( $n^{\circ} 27$, EITallar).

colapso al hundimiento de cavidades kársticas más profundas que en el resto de casos, y que hayan arrastrado toda la columna vertical suprayacente.

\section{Análisis de la susceptibilidad del terreno a que se pro- duzcan nuevos colapsos}

Como se ha descrito en los apartados anteriores, en la zona de estudio se produce una elevada actividad en lo que se refiere a hundimientos del terreno por colapso. El simple hecho de tratarse de un karst carbonatado está indicando que la probabilidad de que se formen nuevos colapsos es, en cierto modo, significativa. En este sentido, la mejor forma de evitar los daños personales y materiales sería la posibilidad de poder anticiparse desde el punto de vista espacio-temporal a su aparición, pero nos encontramos con el problema de que en la actualidad la predicción de este tipo de fenómenos es inviable, sobre todo en un área de grandes dimensiones. Sería necesaria la realización de una importantísima campaña geofísica, geológica, geomorfológica y de instrumentación que caracterice minuciosamente toda la zona afectada por los hundimientos.

En cambio sí se pueden plantear, en forma de hipótesis, algunas consideraciones sobre la posible distribución espacial de futuros colapsos del terreno, sobre todo a través de la delimitación de aquellas zonas que, desde el punto de vista hidrogeológico y geomorfológico, cumplen con las características adecuadas para que se pueda producir este fenómeno.

Los hundimientos del terreno pueden traer consigo graves daños en las infraestructuras, así como poner en peligro la vida de las personas cuando éstos se generan de forma repentina, suponiendo así mismo un riesgo para la maquinaria e infraestructuras utilizadas para la agricultura. La mayor parte de los colapsos registrados hasta el momento se han producido en zonas agrícolas, pero también en zonas de Dominio Público Hidráulico. En este sentido, cabe señalar que en la zona de estudio se ubica parte de la superficie de dos municipios (Villarrubia de los Ojos y Daimiel), que en conjunto albergan una población cercana a los 30.000 habitantes y que, al menos deben estar al corriente de este fenómeno en la medida de lo posible, para evitar daños personales y materiales.

El aspecto sin duda más importante para analizar la susceptibilidad por nuevos colapsos es el nivel piezométrico, que aporta una primera diferenciación a la hora de localizar zonas vulnerables por colapsos. La cota piezométrica a la que ha colapsado el terreno oscila entre los $598 \mathrm{~m}$ s.n.m. (colapsos 24 y 25) y los 611 m s.n.m. (colapsos 7 y 17); por tanto la diferencia entre la máxima y la mínima es de 13 metros. De ascender el nivel piezométrico hasta una situación semejante a la existente en el año 1980, asimilada al régimen natural, la diferencia podría llegar a ser de 16 metros, por lo que las posibles modificaciones o variaciones en los flujos de agua subterránea podrían provocar la aparición de nuevos colapsos.

Para analizar este fenómeno, se ha considerado la susceptibilidad de la zona, de acuerdo con la clasificación de colapsos realizada (tabla 3), con la excepción de los colapsos de tipo intermedio. Para ello se han elaborado unos mapas de susceptibilidad del terreno a nuevos colapsos, entendiendo susceptibilidad como la probabilidad de ocurrencia de este tipo de fenómenos. En este sentido, nos hemos basado en una visión retrospectiva, en la que se han tenido en cuenta los colapsos actualmente presentes en cada una de las tipologías clasificadas, calificando de este modo las zonas de acuerdo con la mayor o menor predisposición a la formación de colapsos.

\section{Susceptibilidad por nuevos colapsos en áreas fluvia- les, por flujos subhorizontales}

El estudio de este tipo de zonas se ha realizado mediante un análisis de proximidad, con la realización de un mapa donde se representan, a través del área de influencia de los cauces de los ríos, aquellas zonas en las que es más probable que se puedan producir colapsos, teniendo en cuenta los ya presentes en la zona de estudio (figura 13). La zona se califica según 


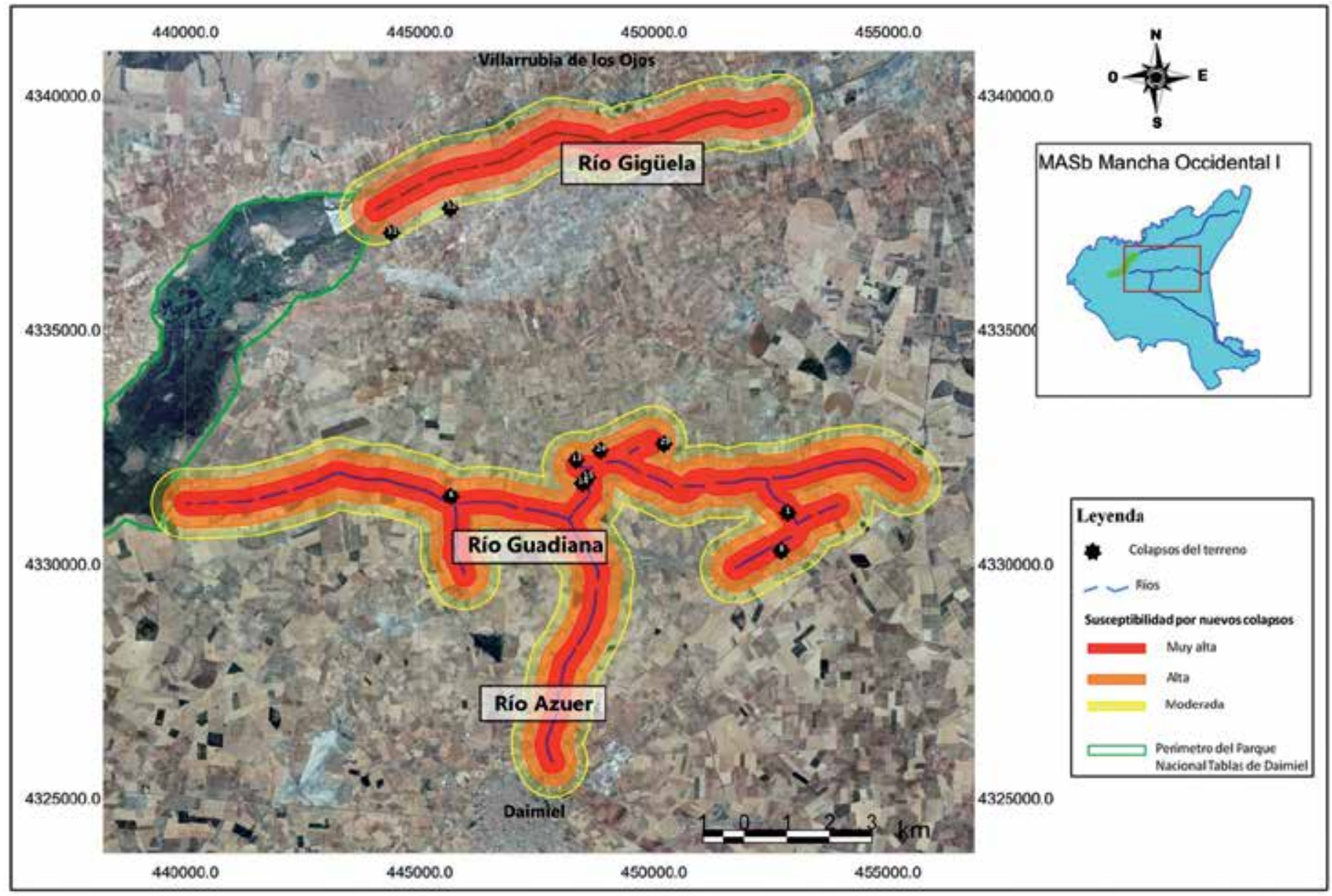

Figura 13. Mapa de susceptibilidad por nuevos colapsos en áreas fluviales con flujos subhorizontales. Ortofotografía del PNOA, CNIG (IGN). Figure 13. Susceptibility map for new collapses in fluvial areas with subhorizontal flows. Orthophotograph of PNOA, CNIG (IGN).

presente una susceptibilidad muy alta (hasta 250 metros desde del cauce), alta ( 500 metros) o moderada (750 metros).

Dentro de las zonas con mayor susceptibilidad por colapsos cabría señalar todo el cauce del río Guadiana, desde su nacimiento en los Ojos del Guadiana, hasta su llegada al Parque Nacional de Las Tablas de Daimiel. Gran parte de los flujos subterráneos se dirigen hacia esta zona, al ser desde el punto de vista topográfico y piezométrico la más baja, constituyéndose como rebosadero natural de la MASb, y por lo tanto sufriendo más afecciones kársticas con el aumento del nivel freático. Al igual que el río Guadiana, también se puede establecer cierto riesgo en el tramo bajo del cauce de los ríos Azuer y Gigüela. La delimitación no es aleatoria, sino que se han tenido en cuenta aquellas zonas más próximas a los ríos, en las que el nivel piezométrico se encuentra, al menos, a 11 metros de profundidad.

\section{Susceptibilidad por nuevos colapsos en zonas de turba}

La presencia de importantes espesores de turba, concretamente en el cauce del río Guadiana, es un factor de riesgo a tener en cuenta a la hora de analizar dónde es probable que se produzcan nuevos colapsos del terreno. La Confederación Hidrográfica del Guadiana delimitó las turberas del Guadiana (Delgado, 1993). Basándonos en dicha información, se han digitalizado las zonas que cuentan con al menos un metro de espesor de turba en el cauce del río Guadiana (figura 14), que a su vez son en las que se han producido colapsos actuales, delimitando así la zona con mayor riesgo de hundimiento, en este caso por autocombustión de la turba.

Hasta el momento, los colapsos que se han producido dentro de esta tipología se localizan en las turberas del cauce medio del tramo comprendido 
Bórnez Mejías, K., et al., 2017. Inventario, clasificación y génesis de los colapsos del... Boletín Geológico y Minero, 128 (1): $43-68$

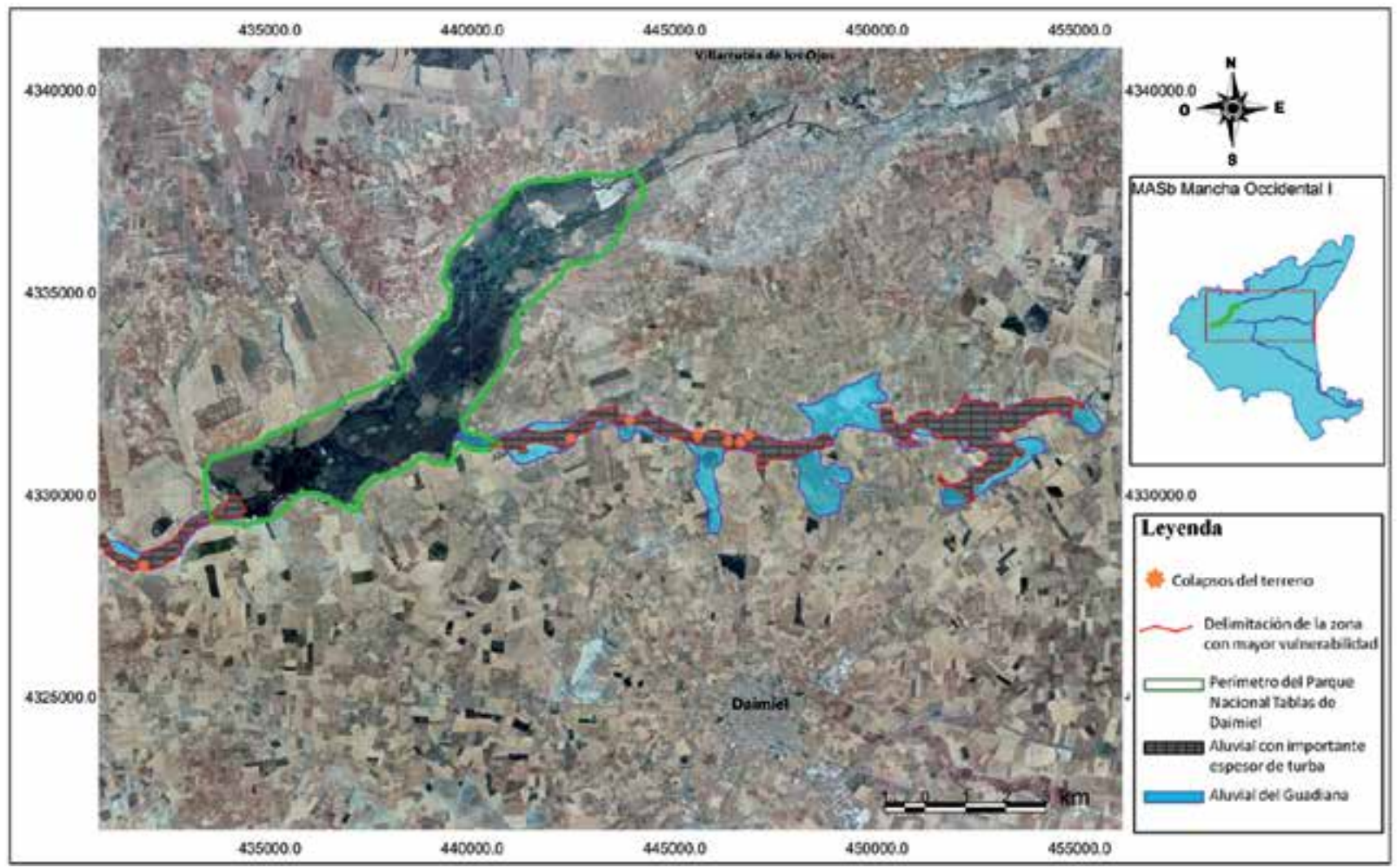

Figura 14. Mapa de susceptibilidad por nuevos colapsos en zonas con turba. Ortofotografía del PNOA, CNIG (IGN).

Figure 14. Susceptibility map for new collapses in areas with peat. Orthophotograph of PNOA, CNIG (IGN).

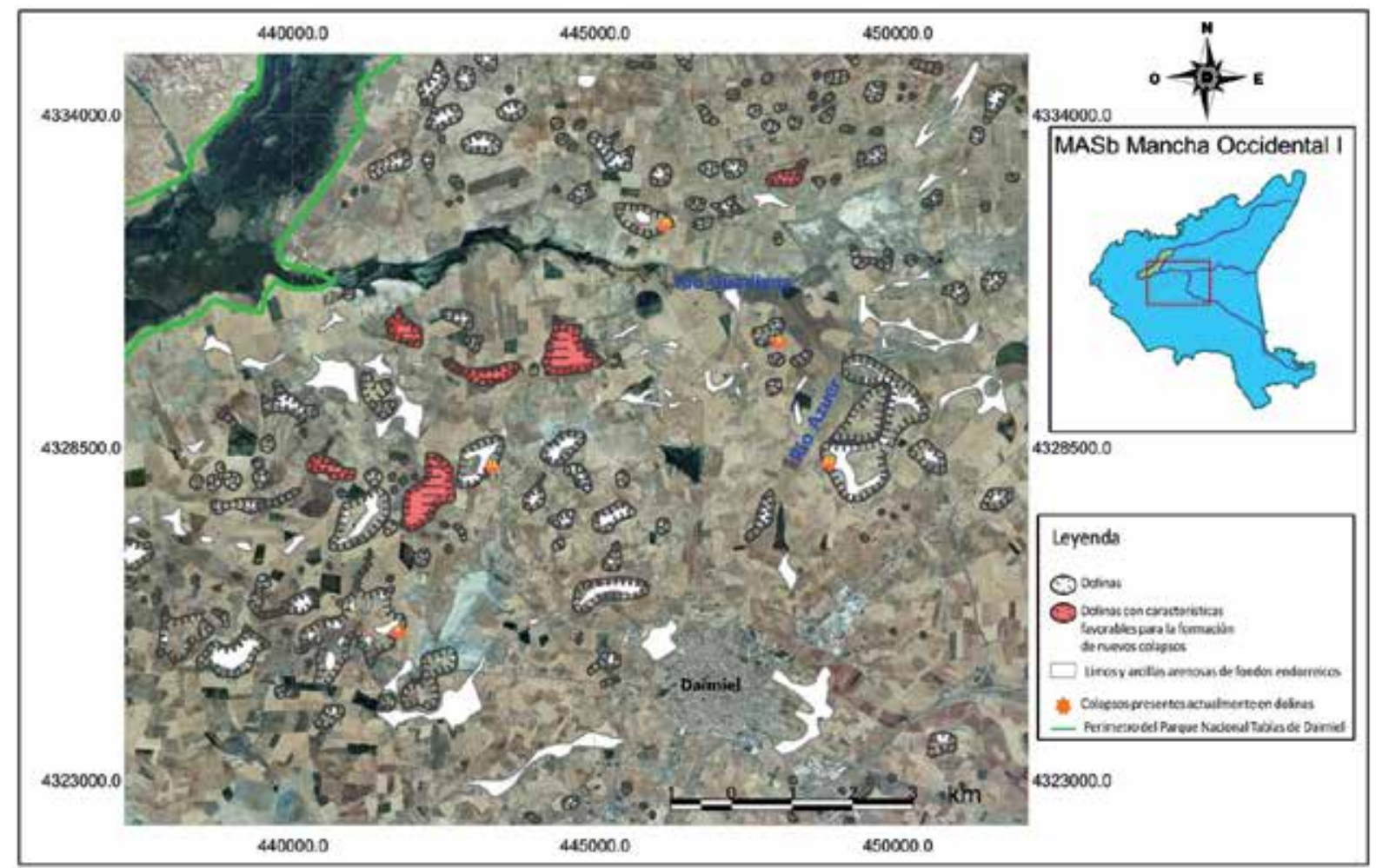

Figura 15. Mapa de susceptibilidad por nuevos colapsos en zonas de dolina. Ortofotografía del PNOA, CNIG (IGN).

Figure 15. Susceptibility map for new collapses in dolinas areas. Orthophotograph of PNOA, CNIG (IGN). 


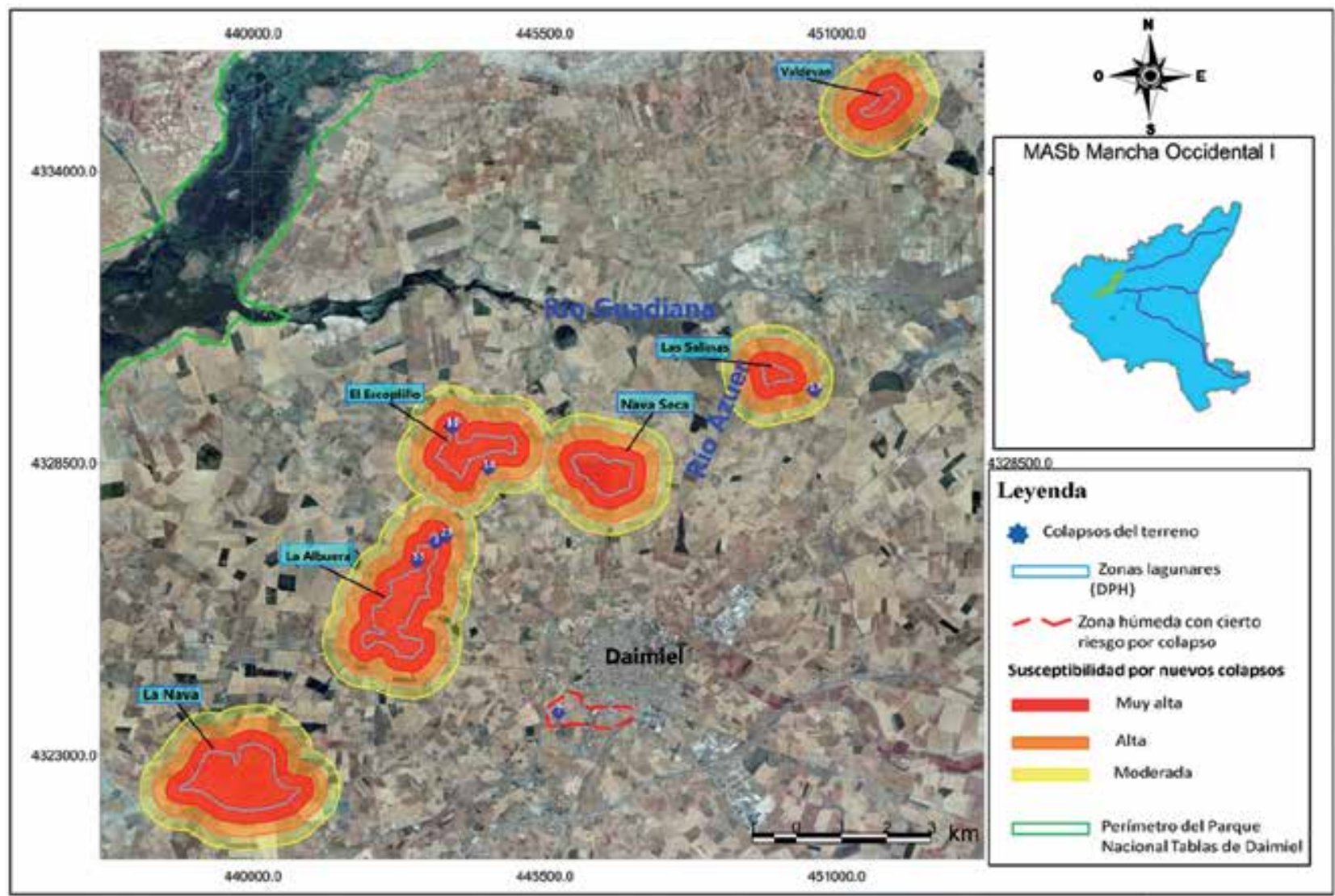

Figura 16. Mapa de susceptibilidad por nuevos colapsos en zonas lagunares. Ortofotografía del PNOA, CNIG (IGN).

Figure 16. Susceptibility map for new collapses in lagoons areas. Orthophotograph of PNOA, CNIG (IGN).

entre el nacimiento del río Guadiana y el Parque Nacional. Se ha detectado una zona de turba próxima al nacimiento en la que no se han detectado colapsos hasta el momento. Se considera que esta zona presenta una muy alta probabilidad de colapso, en el caso de que se produjera una nueva situación de autocombustión.

\section{Susceptibilidad por nuevos colapsos en zonas de dolina}

Para el siguiente análisis ha sido muy importante la utilización del Sistema de Información Geográfica (SIG), a través del cual se han seleccionado, por un lado, aquellas dolinas cuyas dimensiones son iguales o mayores con respecto a las dolinas más pequeñas en las que ya se han producido colapsos. Junto a ello, también se ha tenido en cuenta la altura del nivel piezométrico actual, calculado en la zona más baja de la dolina.

Una vez obtenidos ambos resultados, se han seleccionado tan solo aquellas dolinas en las que el nivel piezométrico se encuentra a 14 o más metros de profundidad (figura 15), que según el criterio utilizado, serían las zonas más susceptibles de sufrir nuevos colapsos por flujos verticales.

\section{Susceptibilidad por nuevos colapsos en zonas lagunares}

Al igual que se hizo en el análisis de las zonas fluviales, hemos cartografiado un área de influencia, aplicándolo a cada una de las lagunas, ya que de las seis que se tiene constancia (La Nava, La Albuera, EI Escoplillo, Nava Seca, Las Salinas y Valdevao) es en tres de ellas en las que actualmente existen colapsos (La Albuera, El Escoplillo y Las Salinas), tal y como se representa en la figura 16 . Por tanto, nada hace pensar que no se vayan a producir en alguna de las otras lagunas, aunque bien es cierto señalar que, por la altura piezométrica, es más que probable que de producirse lo hagan nuevamente en el entorno de la laguna de la Albuera y El Escoplillo. 


\section{Conclusiones}

La zona estudiada está constituida principalmente por materiales del Terciario y Cuaternario, litológicamente formada por depósitos detríticos, calizas, calizas margosas y rañas, dando lugar a un importante acuífero regional. Es precisamente la existencia del material carbonatado, lo que ha propiciado la intensa karstificación por disolución de la zona, con la existencia de conductos kársticos, parte de los cuales se están hundiendo, dando lugar a la aparición de colapsos.

En total, se han inventariado 34 colapsos, que datan de los años 1997, 2010, 2011 y 2013. Estos hundimientos no tienen las mismas características desde el punto de vista geomorfológico e hidrogeológico. No todos tienen las mismas formas, aunque la mayoría tienden a una configuración circular, pero lo más importante es que no todos tienen el mismo tamaño. En este sentido, se ha apreciado que los colapsos producidos en el año 2010 cuentan por lo general con un diámetro mayor que los producidos en los años sucesivos, al igual que los colapsos de 2011 son mayores que los de 2013. Es decir, conforme el nivel piezométrico ha ido ascendiendo, los colapsos producidos han sido cada vez de menor diámetro, lo que da pie a pensar que el karst en profundidad está más desarrollado y que, de producirse nuevos colapsos, serán de menores dimensiones. Otra hipótesis que puede explicar este comportamiento es que una vez desplomadas las cavidades kársticas de mayor tamaño, lo que quedan son conductos kársticos y/o huecos de menor entidad.

Analizando la evolución piezométrica, en puntos de medida cercanos a los colapsos del terreno, se ha podido comprobar que a partir de 2010 se produce un considerable ascenso del nivel piezométrico, donde destaca principalmente la rapidez del proceso. En apenas 4 años se han recuperado niveles que no se observaban desde mediados de los años 80 del pasado siglo, hecho atribuible al último periodo húmedo (2009/2013), en que las precipitaciones han sido muy abundantes, contribuyendo a una rápida recarga del acuífero. Todo parece indicar que ha sido el propio ascenso piezométrico el principal responsable de que se produzcan los colapsos del terreno, pero no tanto por disolución reciente del material calizo, sino más bien por el proceso de recirculación del agua por los conductos kársticos antiguos, así como el ensanchamiento de los mismos como resultado de la disolución y de hundimientos continuos.

En el fenómeno de formación de estos colapsos hay que tener en cuenta tanto los descensos como los ascensos del nivel piezométrico. El descenso está motivado por la sobreexplotación y las prolongadas secuencias climatológicas secas. Este es el fenómeno más importante, ya que deja grandes huecos vacíos, que posteriormente volverían a ser ocupados por el agua en una segunda fase de ascenso hídrico. En la fase de descenso se resquebrajarían las rocas carbonatadas y, en el posterior ascenso se desgajarían por completo y se desplomarían hasta el fondo de la caverna, provocando un colapso en superficie. Estos ascensos piezométricos bruscos vienen precedidos de un largo periodo de descenso continuado, aunque suave; de ahí que los colapsos no se produzcan en esta primera fase como sí ocurre en otros lugares del planeta, sino en la segunda.

Los colapsos del terreno se han producido durante aquellos años en los que el ascenso piezométrico ha sido mayor, lo que explica que en el año 2012 no se registrara ninguno, ya que las precipitaciones fueron escasas durante el año hidrológico 2011/2012 y los niveles piezométricos ascendieron en menor medida, debido a la inercia del acuífero con respecto a las precipitaciones de los años anteriores.

Analizando las isopiezas, también se ha comprobado que los colapsos producidos en el año 2010 se encuentran en la zona más occidental de la MASb, y conforme el nivel fue ascendiendo se desplazaron hacia el este, como ocurrió en el año 2011. En cambio, en el año 2013 , todos los colapsos se produjeron en zonas cercanas a lagunas y en este caso se encontraban distribuidos por la zona central de la MASb.

La recuperación piezométrica también ha tenido sus repercusiones en relación con los cursos fluviales, que han pasado de comportarse como influentes, es decir, perdedores, a actuar como efluentes (ganadores) en algunos tramos, tal y como muestran las isopiezas.

Además de este tipo de colapsos puramente kársticos, también se han localizado otros cuyo origen se encuentra en los huecos dejados por la autocombustión de la turba presente en el cauce del río Guadiana, los cuales no han soportado el peso del material suprayacente, y han terminado por colapsar. Destaca sobre todo la combustión de turba producida en el otoño de 2009.

En relación a la génesis de los colapsos, y de acuerdo a la información hidrogeológica y geomorfológica obtenida en cada uno de ellos, se han clasificado en cuatro grupos de acuerdo a sus características: colapsos aluviales (por turba o por flujos horizontales de descarga), colapsos en dolinas (flujos verticales), colapsos lagunares (flujos horizontales en zonas de recarga) y colapsos de tipo intermedio (flujos verticales u horizontales).

En la actualidad, la predicción espacio-temporal 
de este tipo de fenómenos es complicada y costosa. No obstante, en base a los datos obtenidos, se han realizado una serie de mapas sobre la posible distribución espacial de futuros colapsos del terreno, sobre todo a través de la delimitación de aquellas zonas que desde el punto de vista hidrogeológico y geomorfológico cumplen con las características adecuadas para que se pueda producir este fenómeno.

Las zonas que se consideran con mayor susceptibilidad a nuevos colapsos serían sobre todo las aluviales del río Guadiana y, en menor medida, Gigüela y Azuer, tanto por flujos horizontales como por autocombustión de turba, así como las lagunas y su entorno. En cuanto a los colapsos en zonas de dolinas, a través de un cálculo estadístico, se han seleccionado aquellas dolinas que cuentan con condiciones adecuadas para que se produzcan colapsos, casi todas ellas en la zona sureste del Parque Nacional de las Tablas de Daimiel, cercanas a la laguna de la Albuera y de El Escoplillo.

\section{Agradecimientos}

El presente artículo tiene como base las prácticas y el Proyecto Fin de Máster realizado en el Instituto Geológico y Minero de España (IGME), bajo la dirección de D. Miguel Mejías Moreno y D. Alfredo García de Domingo, para el Máster en Recursos Hídricos y Medio Ambiente de la Universidad de Málaga (UMA). Así mismo, parte de las prácticas se desarrollaron en las oficinas de la Confederación Hidrográfica del Guadiana en Ciudad Real, bajo la dirección de D. Carlos Delgado Velasco, que facilitó valiosa información para el desarrollo de este trabajo.

Agradecer también la colaboración de Doña Carmen Antón-Pacheco Bravo, quien aportó información sobre teledetección y expertos consejos para la elaboración de este artículo.

\section{Referencias}

Aley, T.J., Williams, J.H., y Massello, J.W. 1972. Groundwater contamination and sinkhole collapse induced by leaky impoundments in soluble rock terrain. Missouri Geological Survey and Water Resources. Engineering Geology Series $n^{\circ}$ 5, 40 pp.

Andreu, J.M., Pulido, A., Rodríguez, T. y García, E. 2004. Sobreexplotación de acuíferos kársticos. En: Investigaciones en sistemas kársticos españoles. Instituto Geológico y Minero de España. Serie Hidrogeología y Aguas Subterráneas, $\mathrm{n}^{\circ}$ 12, 161-184.

Confederación Hidrográfica del Guadiana. 2013. Propuesta para la declaración de la Masa de Agua Subterránea Mancha Occidental l en riesgo de no alcanzar el buen estado cuantitativo y químico. Documento Técnico. Oficina de Planificación Hidrológica.

Cruces, J. y Martínez, L. 2000. La Mancha Húmeda. Explotación intensiva de las aguas subterráneas en la cuenca alta del río Guadiana. Papeles del proyecto aguas subterráneas. Fundación Marcelino Botín, Serie A, $n^{\circ}$ 3, Madrid, $66 \mathrm{pp}$.

Delgado, C. 1993. Estudio, delimitación, propuesta de actuaciones y señalización de las turberas en el tramo del cauce del río Guadiana comprendido entre los Ojos del Guadiana y la cola del embalse del Vicario, salvo la zona de las Tablas de Daimiel. Confederación Hidrográfica del Guadiana. Estudio 06/93. Ciudad Real, Dirección General de Calidad de las Aguas.

García Rodríguez, M. y Llamas, M.R. 1992. Aspectos hidrogeológicos en relación con la génesis y combustión espontánea de las turbas de los Ojos del Guadiana. Actas sesiones científicas III Congreso geológico de España y VII Congreso latinoamericano de geología, Salamanca, Tomo 2, 285-289.

García Rodríguez, M. y Llamas, M.R. 1993. Cambios paisajísticos en el Alto Guadiana causados por la explotación intensiva e incontrolada de aguas subterráneas. Actas de las VI Jornadas sobre el Paisaje, Segovia, 91- 102.

García Rodríguez, M. 1996. Hidrogeología de las Tablas de Daimiel y de los Ojos del Guadiana. Bases hidrogeológicas para la clasificación funcional de humedales ribereños. Tesis Doctoral. Universidad Complutense de Madrid, Madrid.

García Rodríguez, M. y Llamas, M.R. 1996. Características geológicas del borde suroccidental de la Unidad Hidrogeológica 04.04 y su influencia sobre la hidrogeología de Las Tablas de Daimiel. Geogaceta, 20 (6), $1271-1273$.

González, E. y Vázquez, A. 2007. El relieve. En: Pillet Capdepón, F. (ed.), Geografía de Castilla-La Mancha. Editorial Almud, Ciudad Real, 37-54.

Gutiérrez, F. 2004. El riesgo de dolinas de subsidencia en terrenos evaporíticos. Investigación y mitigación. $1^{\circ}$ Seminario Stato dell'arte sullo studio dei fenomeni di sinkholes e ruolo delle amministrazioni statali e local nel governo del territorio, Roma, 453-466.

IGME. 1979. Investigación hidrogeológica de la cuenca alta y media del Guadiana. Informe final (Sistema 19: Sierra de Altomira, Sistema 20: Mancha de Toledo, Sistema 22: Cuenca del río Bullaque, Sistema 23: Llanura Manchega, Sistema 24: Campo de Montiel). Plan Nacional de Investigación en Aguas Subterráneas (PIAS).

IGME, 1985. Mapa Geológico de España, MAGNA, hoja 760, Daimiel, escala 1:50.000.

IGME, 2000. Mapa geológico de España, MAGNA, hoja 737, Villarrubia de los Ojos, escala 1:50.000.

Keqiang, H., Shengquan, Z., Fei, W. y Wen, D. 2010. The karst collapses induced by environmental changes of the groundwater and their distribution rules in North China. Environ Earth Sci, 61, 1075-1084.

Mejías, M., López, J. y Martínez, L. 2012a. Características 
hidrogeológicas y evolución piezométrica de la Mancha Occidental. Influencia del periodo húmedo 2009-2011. Boletín Geológico y Minero, 123 (2), 91-108.

Mejías, M., Martínez, L. y Galindo, M. E. 2012b. Estudio hidrometereológico y análisis del efecto del período húmedo 2009-2010 en la cuenca alta del río Guadiana. En: Fernández Ruiz, L. (ed.), Las aguas subterráneas en la planificación hidrológica. Instituto Geológico y Minero de España, Madrid, 379-396.

Mejías, M. 2014. El agua protagonista a través de los siglos. En: Mejías, M. (ed.), Las Tablas y los Ojos del Guadiana: agua, paisaje y gente. Instituto Geológico y Minero de España-Organismo Autónomo de Parques Nacionales, Madrid, 17-63.
Mejías, M. 2015. Informe sobre la situación hidrológica de las tres masas de agua subterránea centrales de la cuenca alta del río Guadiana. Informe para el Pleno del Patronato del Parque Nacional de las Tablas de Daimiel.

Montero, E. 1994. Funcionamiento hidrogeológico del sistema de las Lagunas de Ruidera. Tesis Doctoral. Universidad Complutense de Madrid, Madrid.

Montero, E. 2000. Contribución al estudio de la geometría y los límites del acuífero del Campo de Montiel. Volumen 119 de Instituto de Estudios Albacetenses "Don Juan Manuel", Serie I-Estudios, Albacete, 177 pp.

Rodríguez, T. 2004. Los humedales de la provincia de Albacete y las aguas subterráneas. Il Jornadas sobre el Medio Natural Albacetense, Albacete, 587-61.

Recibido: julio 2015

Revisado: octubre 2015

Aceptado: marzo 2016

Publicado: marzo 2017 
